Review Article

\title{
Role of Oxidative Stress in Reperfusion following Myocardial Ischemia and Its Treatments
}

\author{
Mi Xiang, ${ }^{1}$ Yingdong Lu $\left(\mathrm{D},{ }^{1}\right.$ Laiyun Xin $\left(\mathrm{D},{ }^{1,2}\right.$ Jialiang Gao, ${ }^{1}$ Chang Shang ${ }^{\mathrm{D}},{ }^{1} \mathrm{Zhilin}$ Jiang $(\mathrm{D}){ }^{1}$ \\ Hongchen Lin $\mathbb{D}^{\mathrm{D}},{ }^{1}$ Xuqin Fang, ${ }^{1}$ Yi Qu ${ }^{\mathbb{D}},{ }^{1}$ Yuling Wang, ${ }^{1}$ Zihuan Shen, ${ }^{1}$ Mingjing Zhao $\left(\mathbb{D},{ }^{3}\right.$ \\ and Xiangning Cui $\mathbb{D}^{1}$
}

\author{
${ }^{1}$ Department of Cardiovascular, Guang'anmen Hospital, China Academy of Chinese Medical Sciences, Beijing, China \\ ${ }^{2}$ First Clinical Medical School, Shandong University of Chinese Medicine, Shandong, China \\ ${ }^{3}$ Key Laboratory of Chinese Internal Medicine of Ministry of Education, Dongzhimen Hospital, Beijing University of \\ Chinese Medicine, Beijing, China
}

Correspondence should be addressed to Mingjing Zhao; mjgx2004@163.com and Xiangning Cui; cuixiangning@126.com

Received 30 November 2020; Revised 21 February 2021; Accepted 29 April 2021; Published 18 May 2021

Academic Editor: Carlo G. Tocchetti

Copyright ( $2021 \mathrm{Mi}$ Xiang et al. This is an open access article distributed under the Creative Commons Attribution License, which permits unrestricted use, distribution, and reproduction in any medium, provided the original work is properly cited.

\begin{abstract}
Myocardial ischemia is a disease with high morbidity and mortality, for which reperfusion is currently the standard intervention. However, the reperfusion may lead to further myocardial damage, known as myocardial ischemia/reperfusion injury (MI/RI). Oxidative stress is one of the most important pathological mechanisms in reperfusion injury, which causes apoptosis, autophagy, inflammation, and some other damage in cardiomyocytes through multiple pathways, thus causing irreversible cardiomyocyte damage and cardiac dysfunction. This article reviews the pathological mechanisms of oxidative stress involved in reperfusion injury and the interventions for different pathways and targets, so as to form systematic treatments for oxidative stress-induced myocardial reperfusion injury and make up for the lack of monotherapy.
\end{abstract}

\section{Introduction}

Myocardial ischemia is the most frequent form of cardiovascular disease with high morbidity and mortality [1], for which timely restoration of blood flow to the ischemic myocardium (reperfusion) is indispensable for a better patient outcome [2]. However, this reperfusion may cause further myocardial ischemia/reperfusion injury (MI/RI) which leads to cardiac dysfunction such as myocardial stunning, reperfusion arrhythmia, myocyte death, and endothelial and microvascular dysfunction including the no-reflow phenomenon, inflammatory response $[3,4]$, and other myocardial tissue injury more terrible than that caused by the original ischemic insult [5]. Lethal reperfusion injury, according to a report, accounts for up to $50 \%$ of the final myocardial infarct size [5]. Among the complex system networks involved in the pathological mechanisms of MI/RI, such as oxidative stress [6], inflammatory response [7], calcium overload [8], and mitochondrial dysfunction [9], one of the most important pathological mechanisms is oxidative stress (OS) [10].

OS refers to an imbalance between normal oxidant scavenging enzyme systems, such as superoxide dismutase, catalase, and glutathione, and intracellular reactive oxygen species (ROS) production, which leads to toxic accumulations of reactive oxygen intermediates like hydrogen peroxide $\left(\mathrm{H}_{2} \mathrm{O}_{2}\right)$ [11, 12]. Under physiological condition, ROS are produced as a result of normal cellular metabolism processes, maintaining a dynamic balance with antioxidants [12]. But ROS can also be generated in both ischemia [13-15] and reperfusion period [16, 17]. Limited oxygen availability during the ischemic period is associated with acidosis, energy depletion, and alterations of ion homeostasis, leading to cardiac dysfunction and ultimately cell death [18]. In the presence of residual oxygen, ROS are produced in the myocardium [18], which are attributed to the decrease of endogenous ROS scavenger and increase of ROS production 
by several mechanisms $[13,19-21]$. Much higher levels of oxygen free radical (OFR) production are induced immediately following reperfusion due to the sudden reintroduction of high oxygen tensions [19], leading to oxidative damage of cell structures, such as initiating lipid peroxidation, protein carbonylation, and DNA oxidation [22]. However, many traditional antioxidants do not show significant efficacy $[23,24]$. The formation and development of oxidative stress after reperfusion and how it affects injuries involve multiple mechanisms, so developing interventions that act on specific pathways rather than simple antioxidants may be a promising therapeutic approach.

Here, through summarizing pathogenesis of oxidative stress involved in MI/RI, including sources of ROS, ROSmediated MI/RI, and its related pathways and signaling molecules, as well as various interventions targeting them, we expect systematic treatments against oxidative stressinduced myocardial reperfusion injury to be formed, complications like arrhythmias, myocardial stunning, microvascular obstruction and myocardial remodeling to be inhibited, and mortality following reperfusion to be reduced.

\section{Sources of ROS}

Amounts of potential sources of ROS in the postischemic heart are most attributed to one or more enzymes like xanthine oxidase [25], NADPH oxidase (NOX) [26, 27], mitochondria [28], and uncoupled nitric oxide synthase [29], which have been deemed as the most likely causes to oxidative stress during reperfusion and thus the most promising targets for therapeutic measures against reperfusion-induced organ dysfunction and tissue damage [30]. In addition to the above mentioned data, there are also some descriptions about other sources such as monoamine oxidases, lipoxygenases, cyclooxygenases, the cytochrome P450, neutrophils, and catecholamine [4, 31-34]. We summarized the various sources of ROS (Figure 1).

2.1. Mitochondria. Mitochondria are deemed the major intracardiac source of ROS RI, impaired autopha/RI [35]. There are at least eleven different sites that associate with substrate catabolism and the electron transport chain (ETC) in mammalian mitochondria generating superoxide and/or hydrogen peroxide [18]. Mitochondrial ROS production involves oxidative phosphorylation linked to aerobic respiration within the mitochondrial ETC [36]. This mechanism has been detailedly described by Cadenas [18]. Electrons are released to cofactors such as NADH and FADH2 via oxidation of substrates and then flow sequentially through a series of redox carriers in respiratory chain complexes, finally reducing oxygen to water with the catalysis by cytochrome c oxidase $(\mathrm{CcO})$. However, at seven different sites along the respiratory chain, electrons derived from $\mathrm{NADH}$ or some other donor can directly react with oxygen and generate $\mathrm{O}_{2}{ }^{-}$[37], that is electron leakage from the ETC at complexes upstream of $\mathrm{CcO}$, primarily at complexes $\mathrm{I}$ and III, causing partial reduction of molecular oxygen to $\mathrm{O}_{2}{ }^{-}$instead of reduction to $\mathrm{H}_{2} \mathrm{O}$ [18], and, among these, reverse electron transport at complex I is the main source of superoxide upon reperfusion of ischemic tissue [38, 39]. $\mathrm{O}_{2}{ }^{-}$can be converted into $\mathrm{H}_{2} \mathrm{O}_{2}$ and $\mathrm{O}_{2}$ either spontaneously or enzymatically catalyzed by superoxide dismutase (SOD) $[18,40]$. Hydrogen peroxide $\left(\mathrm{H}_{2} \mathrm{O}_{2}\right)$ can be fully reduced to water or partially reduced to the hydroxyl radical $(\bullet \mathrm{OH})$ [18]. $\mathrm{H}_{2} \mathrm{O}_{2}$ oxidizes $\mathrm{Fe}^{2+}$ to $\mathrm{Fe}^{3+}$ to generate hydroxyl radicals through the Fenton reaction $[18,35]$ and also reacts with $\mathrm{O}_{2}{ }^{-}$ to generate $\bullet \mathrm{OH}$ in the Haber-Weiss reaction $[19,35]$. Glutathione peroxidase catalyzes $\mathrm{H}_{2} \mathrm{O}_{2}$ to form nonradical water and oxygen [35].

2.2. Xanthine Oxidoreductase. Xanthine oxidoreductase, the major source of superoxide in postischemic tissue too [4], consists of two interconvertible forms, xanthine dehydrogenase $(\mathrm{XDH})$ preferably using $\mathrm{NAD}^{+}$as an electron acceptor and xanthine oxidase (XO) using $\mathrm{O}_{2}$ as the terminal electron acceptor [30]. Xanthine oxidoreductase catalyzes the transformation of hypoxanthine and xanthine to uric acid, with $\mathrm{O}_{2}{ }^{-}$or $\mathrm{H}_{2} \mathrm{O}_{2}$ generation as by-products $[41,42]$. Moreover, under acidic conditions ( $\mathrm{pH} \sim 6.5$ ), $\mathrm{XDH}$ may oxidize $\mathrm{NADH}$ instead of xanthine, thus promoting superoxide production RI, impaired autopha/RI [30]. Therefore, developing a sort of xanthine oxidoreductase inhibitors seems a promising intervention against MI/RI. But this approach sometimes gets nowhere due to differences in xanthine oxidoreductase abundance/activity between animal species [30]. For instance, application of XO inhibitor, like allopurinol, to the rabbit heart [43] and human heart [44] cannot protect against MI/RI, because the rabbit heart and human heart lack $\mathrm{XO}$ activity. However, activation of XO in hepatoenteric tissue of a rabbit, not in the heart, induced significant myocardial injury [45]. Perhaps because ROS released from extracardiac xanthine oxidase induce cardiac injury [35], and therefore, inhibition of extracardiac xanthine oxidase may be still an effective therapeutic treatment against oxidative stress-induced cardiac injury. In addition, xanthine dehydrogenase is converted to xanthine oxidase during ischemia [42]. In consideration that the capacity of superoxide production by $\mathrm{XDH}$ is regulated by the relative level of $\mathrm{NAD}^{+}$to $\mathrm{NADH}$, and the higher proportion of $\mathrm{NADH}$, the more enhanced $\mathrm{O}_{2}{ }^{-}$production [46], researches for finding an intervention to change the reductive state (low $\mathrm{NAD}^{+}$ to $\mathrm{NADH}$ ratio) during reperfusion period in the heart could be a feasible treatment to protect against MI/RI.

\subsection{Uncoupled Nitric Oxide Synthase. Different effects of NO} from various sources on MI/RI have been reported. NO derived from endothelial nitric oxide synthase and neuronal nitric oxide synthase are thought to protect against MI/RI, while inducible nitric oxide synthase-derived ones aggravate $\mathrm{MI} / \mathrm{RI}$ and can also cause cardiac hypertrophy and oxidative stress [47]. NOS are enzymes containing flavin and heme and transfer electrons from the NADPH at the C-terminal (reductase domain) to the $\mathrm{N}$-terminal heme (oxidase domain), reducing $\mathrm{O}_{2}$ and incorporating it into l-arginine to produce l-citrulline and NO [48, 49]. However, tetrahydrobiopterin (BH4), an essential cofactor of NOS, will be oxidized by ROS [50]. In the absence of l-arginine, $\mathrm{BH} 4$, or both, NOS can become a source of $\mathrm{O}_{2}^{-}$instead of $\mathrm{NO}[48,51]$, thus 


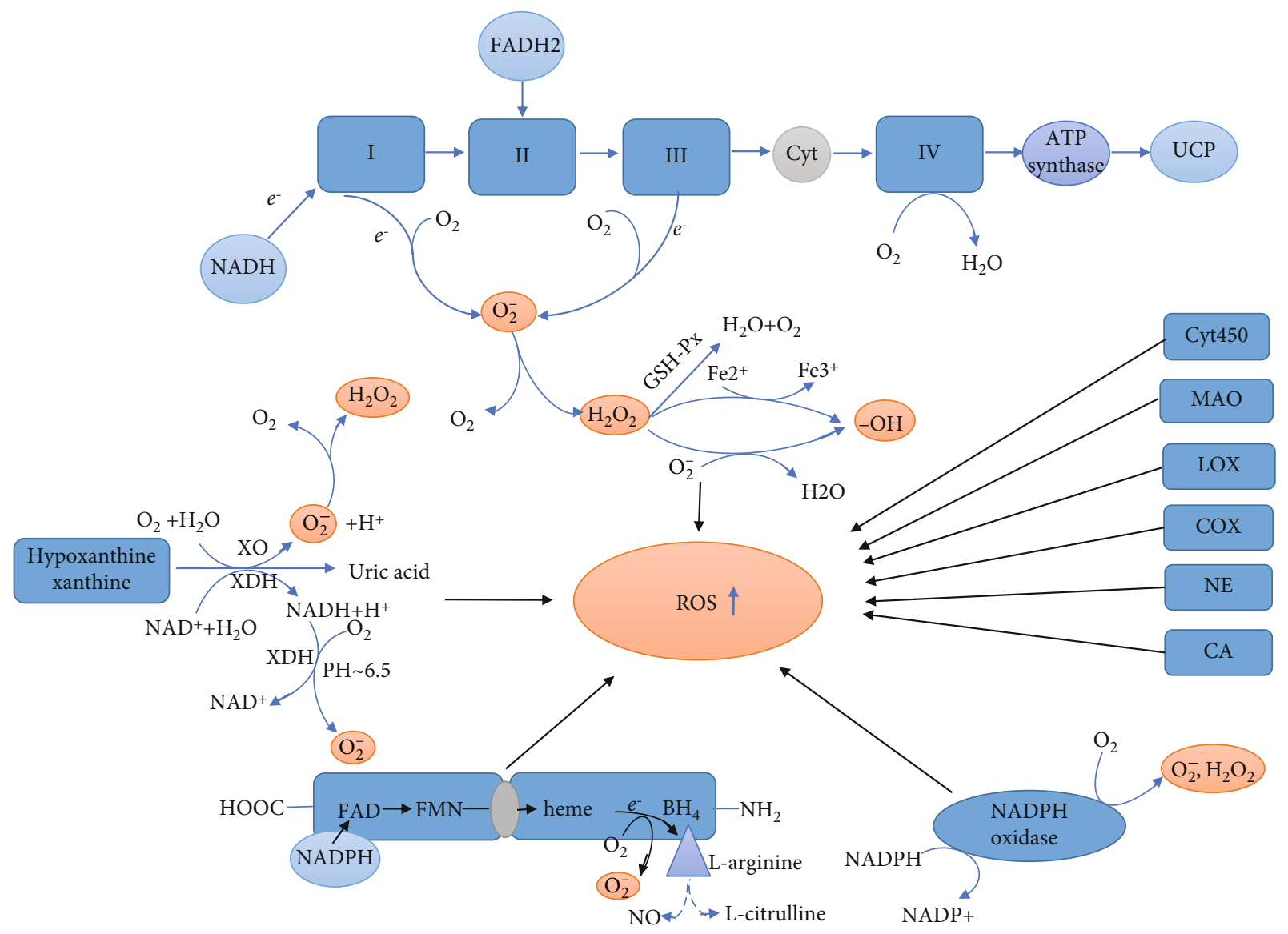

Figure 1: Multiple sources of reactive oxygen species during reperfusion following myocardial ischemia. These are mainly mitochondria, xanthine oxidoreductase, uncoupled nitric oxide synthase, nicotinamide adenine dinucleotide phosphate oxidase, and some other sources. Abbreviations: NADPH: nicotinamide adenine dinucleotide phosphate; NADH: nicotinamide adenine dinucleotide; FADH2: flavin adenine dinucleotide hydrogen transmitter; $\mathrm{O}_{2}^{-}$: superoxide; Cyt: cytochrome; UCP: uncoupled protein; GSH-Px: glutathione peroxidase; $\mathrm{XDH}$ : xanthine dehydrogenase; FAD: flavin adenine dinucleotide; FMN: flavin mononucleotide; BH4: tetrahydrobiopterin; MAO: monoamine oxidase; LOX: lipoxygenases; CA: catecholamine; NE: neutrophil; COX: cyclooxygenase; XO: xanthine oxidase.

becoming "uncoupled" to their primary role of NO synthesis and limiting the effect of $\mathrm{NO}$ in the vascular system. However, $\mathrm{H}_{2} \mathrm{O}_{2}$ could potentially induce and activate the eNOS $[52,53]$ that compensates for the reduction of NO due to the pathological processes above. Besides, it has been speculated that iNOS is increased under reperfusion stimulation and then synthesizes NO $[54,55]$. NO exerts cytotoxic effects both in a direct way and via reacting with superoxide to form highly oxidizing agent peroxynitrite $\left(\mathrm{ONOO}^{-}\right)$that causes further cell and tissue damage $[54,56,57]$.

\subsection{Nicotinamide Adenine Dinucleotide Phosphate (NADPH)} Oxidase. NADPH oxidases (NOXs) are a family of seven transmembrane electron transporters, respectively, named NOX1 to NOX5 and dual oxidase- (DUOX-) 1 and DUOX$2[58,59]$ that catalyze the transfer of electrons across biological membranes from the electron donor NADPH to $\mathrm{O}_{2}$, leading to the generation of $\mathrm{O}_{2}^{-}[59]$ and, according to some reports, $\mathrm{H}_{2} \mathrm{O}_{2}$ [60-62]. To be more specific, it is believed that the dual oxidases and NOX4 predominately produce $\mathrm{H}_{2} \mathrm{O}_{2}$, while the remaining NOX isoenzymes largely produce superoxide $[18,27,60]$. The DUOX proteins are highly expressed mainly in the thyroid [59]. NOX3 is expressed almost exclusively in the inner ear [58]. The other NOX isoforms NOX1, NOX2, NOX4, and NOX5 are expressed in the cardiovascular system and are activated or highly expressed during myocardial ischemia or reperfusion $[18,63]$. NOX2 and NOX4 are the main NOX subtypes that produce ROS especially $\mathrm{O}_{2}{ }^{-}$and $\mathrm{H}_{2} \mathrm{O}_{2}$ in the heart, which promote oxidative stress RI, impaired autopha/RI [64]. NADPH oxidases are involved in other process of ROS production, such as the ROS generation by NOS and xanthine oxidase; NADPH oxidase-derived ROS may oxidize and degrade $\mathrm{BH} 4$ and activate xanthine oxidase $[65,66]$.

\section{Pathways through Which Oxidative Stress Causes Myocardial Reperfusion Injury}

Oxidative stress causes cell death either through directly destroying proteins, DNA, lipids, and other macromolecules or acting as a signal molecule in the cell death signaling pathway [67]. In this part, we mainly discussed the negative effects of ROS in reperfusion through apoptosis, autophagy, 


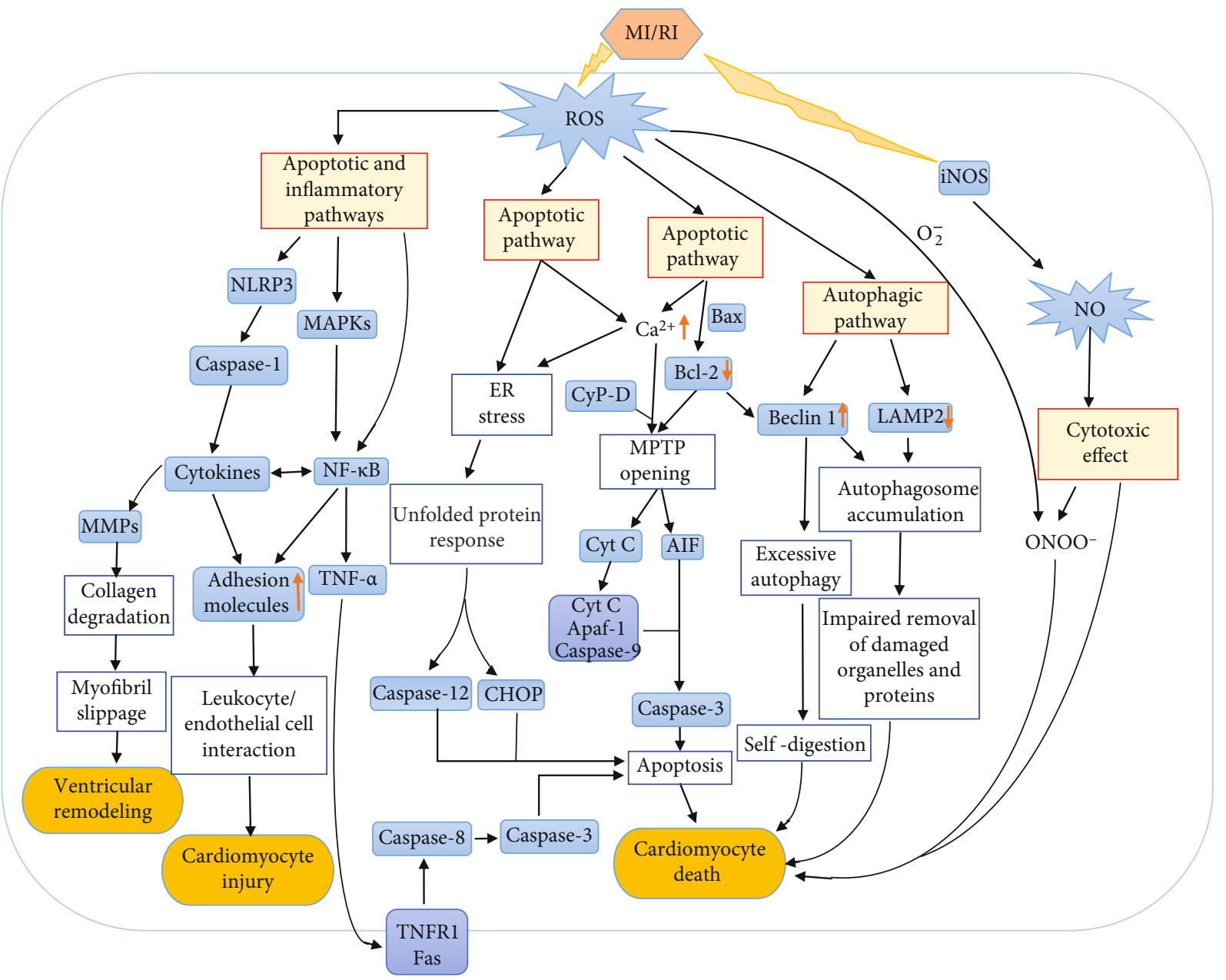

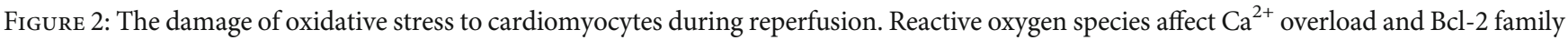
proteins, which lead to the mitochondrial permeability transformation pore opening and ultimately lead to myocardial apoptosis. Reactive oxygen species also trigger exogenous apoptosis by activating the MAPK family. Finally, reactive oxygen species initiate apoptosis through ER stress. Beclin1 and LAMP2, which are regulated by reactive oxygen species, cause impaired autophagy or excessive autophagy, thereby damaging cardiomyocytes. Via inflammatory response, reactive oxygen species induce pathological damage of the heart. NO, one of the members of reactive nitrogen, damages cardiomyocytes through direct cytotoxicity or generates $\mathrm{ONOO}^{-}$with $\mathrm{O}_{2}^{-}$to cause cardiomyocyte damage. Abbreviations: MAPK: mitogen-activated protein kinase; NF- $\kappa$ B: nuclear transcription factor- $\kappa$ B; TNF- $\alpha$ : tumor necrosis factor- $\alpha$; TNFR1: tumor necrosis factor receptor 1; Fas: tumor necrosis factor superfamily; CyP-D: cyclophilin D; Bcl-2: B cell lymphoma-2; MPTP: mitochondrial permeability transition pore; AIF: apoptosis-inducing factor; Cyt: cytochrome; LAMP2: lysosomal-associated membrane protein 2; Apaf-1: apoptosis protease-activating factor-1; $\mathrm{ONOO}^{-}$: peroxynitrite; NLRP3: nucleotide-binding oligomerization domain-like receptor protein 3; MMPs: matrix metalloproteinases; ER stress: endoplasmic reticulum stress; CHOP: CCAAT/enhancer-binding protein homologous protein.

inflammation, and some other pathological process, along with the mechanisms involved (Figure 2).

3.1. Apoptosis of Myocardial Cells Induced by ROS. Apoptosis, a unique form of gene-regulated cell death, has been shown to be triggered or accelerated primarily during reperfusion or reoxygenation $[68,69]$. Secondary necrosis (i.e., late apoptosis) of apoptotic cells can be caused by loss of membrane integrity of these cells [70], ROS-induced inactivation of caspases [71], and oxidant-induced failure of mitochondrial energy production [72]. It was thought that apoptosis might cause myocardial stunning [73], extension of infarction [74], cardiac dysfunction, and even heart failure [75,
76]. Mechanisms of apoptosis induced by ROS have been systematically described [34, 77].

Apoptosis triggered by disruption of mitochondrial homeostasis. $\mathrm{Ca}^{2+}$ is induced by ROS to influx into the cytoplasm and then influx into the mitochondria, resulting in the opening of MPTP, the collapse of mitochondrial membrane potential, and release of apoptotic signaling molecules such as cytochrome $\mathrm{c}$ and apoptosis-inducing factor (AIF) from the intermembrane space [34, 78-80]. In the cytosol, the apoptosome, formed with cytochrome c, apoptosis protease-activating factor-1 (Apaf-1), and caspase-9, activates caspase- 3 ultimately initiating apoptosis [34, 79]. Evidence suggests that $\mathrm{Bcl}-2$ prevents MPTP opening and 
inhibits caspase activity, thereby inhibiting apoptosis. On the contrary, Bax increased mitochondrial outer membrane permeability and caused the release of apoptotic factors [81, 82]. Beyond that mentioned above, oxidative stress also contributes to the translocation of the apoptotic protein Bax and Bad into the mitochondria where these factors form heterodimers with Bcl-2 [83], decreasing Bcl-2. A decreased Bcl2/Bax ratio results in MPTP opening as well [79].

Apoptosis triggered by MAPK family. ROS activate MAPKs (primary p38 and JNK MAPKs), which mediate the dissociation of the NF- $\kappa \mathrm{B}$ from its inhibitor $\mathrm{I} \kappa \mathrm{B}$ and upregulate activated NF- $\kappa \mathrm{B}$ [34]. NF- $\kappa \mathrm{B}$ in the cytoplasm influx into the nucleus, contributing to synthesis of TNF- $\alpha$ that releases to extracellular matrix, combines with membrane surface receptors (TNFR1 and Fas), activates caspase8 and caspase- 3 , and then triggers an extrinsic death cascade [34]. ROS could also directly activate NF- $\kappa \mathrm{B} \cdot \mathrm{H}_{2} \mathrm{O}_{2}$ may directly mediate the dissociation of $\mathrm{I} \kappa \mathrm{B}$ from NF- $\kappa \mathrm{B}$ and upregulate NF- $\kappa \mathrm{B}$ [84]. H/R-induced reactive oxygen intermediates activate NF- $\kappa \mathrm{B}$ via tyrosine phosphorylation of $\mathrm{I} \kappa \mathrm{B} \alpha$ [85]. Evidences of NF- $\kappa \mathrm{B}$ activation by oxidative stress have also been described by Bowie and O’Neill [86]. However, the activation of NF- $\kappa \mathrm{B}$ by $\mathrm{H}_{2} \mathrm{O}_{2}$ is cell-specific [86], and it has not been clarified whether the mechanism of activation above holds in cardiomyocytes.

Apoptosis induced by endoplasmic reticulum stress. RI, impaired autopha/RI, deficiency of glucose and nutrient supply, ATP depletion, ROS accumulation, and destruction of $\mathrm{Ca}^{2+}$ homoeostasis interfere with endoplasmic reticulum (ER) function, causing unfolded protein response with unfol$\mathrm{ded} / \mathrm{misfolded}$ protein accumulation, the condition referred to as ER stress $[87,88]$. Numerous studies have indicated the association between ER stress and cardiomyocyte apoptosis [89]. Prolonged and/or excessive ER stress has been reported to induce ER-related apoptosis with increased expression of CCAAT/enhancer-binding protein homologous protein (CHOP) and the activation of caspase-12 [87, 90]. Simultaneously, ER stress was thought to disrupt the redox balance, causing ROS accumulation and mitochondria dysfunction, finally aggravating cardiomyocyte apoptosis [90].

3.1.1. Effects of ROS on Intracellular $\mathrm{Ca}^{2+}$ Overload. Intracellular $\mathrm{Ca}^{2+}$ overload may be caused via multiple pathways that involved oxygen free radicals. Sarcolemmal $\mathrm{Ca}^{2+}$-ATPase related to the extrusion of $\mathrm{Ca}^{2+}$ from cardiac cells [91] and sarcoplasmic reticular $\mathrm{Ca}^{2+}, \mathrm{Mg}^{2+}$-ATPase sequestering $\mathrm{Ca}^{2+}$ from the cytoplasm into the lumen of sarcoplasmic reticulum [19] are altered by oxygen free radicals. ROSinduced intracellular $\mathrm{Ca}^{2+}$ overload is also reported to be caused via the activation of $\mathrm{Na}^{+} / \mathrm{H}^{+}$exchanger [92], inhibition of $\mathrm{Na}^{+}-\mathrm{K}^{+}$ATPase [92, 93], and enhancement of $\mathrm{Na}^{+} / \mathrm{Ca}^{2+}$ exchange $\left(\mathrm{Ca}^{2+}\right.$ influx, $\mathrm{Na}^{+}$efflux) [94], which all promote influx of $\mathrm{Ca}^{2+}$ into the intracellular space. Besides, increased extracellular $\mathrm{Ca}^{2+}$ influx is caused by ROS through membrane lipid peroxidation and the voltage-sensitive $\mathrm{Ca}^{2+}$ channel opening $[4,95]$.

3.1.2. ROS Promote MPTP Opening. The formation of mitochondrial permeability transition pore (MPTP), an inner membrane nonselective pore, can cause ATP depletion, enhanced ROS production, membrane ion pump failure, solute entry, and then mitochondrial swelling, rupture, and release of apoptotic signaling molecules such as cytochrome c from the intermembrane space; this eventually leads to cardiomyocytes apoptosis, causing irreversible damage to the heart $[4,18]$. The formation and opening of the MPTP are the main cause of mitochondrial dysfunction and cardiomyocyte death [96]. Therefore, prevention of MPTP opening with pharmacological interventions or genetic modifications has been reported to limit infarct size and decrease myocardial apoptosis and necrosis [97, 98]. MPTP have been reported [18] to be promoted by matrix $\mathrm{Ca}^{2+}$ and ROS but inhibited by low $\mathrm{pH}$ in ischemia. However, during reperfusion, restoration of $\mathrm{pH}$, along with mitochondrial calcium overload and excessive ROS generation, causes the pore to form $[18,99]$, leading to cardiomyocyte death. In view of these influence factors, it is extremely significant to seek out some cardioprotective strategies that attenuate matrix calcium overload and oxidative stress or maintain a low $\mathrm{pH}$ during early phase of reperfusion [100-102]. In addition to stimulus above, matrix cyclophilin D (CyP-D) promotes MPTP opening via enhancing its calcium sensitivity [102], and binding of cyclophilin to the inner mitochondrial membrane could be greatly increased by oxidative stress [103]. CyP-D can be targeted by cyclosporin A (CsA) to protect cardiomyocytes [18]. However, the toxicity of cyclosporin [104] and even the adverse effects of $\mathrm{Ca}^{2+}$ efflux disorder in mitochondria after CyP-D-mediated MPTP opening is inhibited $[105,106]$ limit the functions of CsA and other CyP-D inhibitors. However, MPTP opening lasts only for the first few minutes after reperfusion [107] and may have little effect on $\mathrm{Ca}^{2+}$ accumulation in the mitochondrial matrix. As for cyclosporine toxicity, more specific and novel CyP-D inhibitors may be explored.

3.1.3. Activation of MAPK Family. Mitogen-activated protein kinases (MAPKs) are a protein family including extracellular signal-regulated kinases (ERK1 and ERK2), c-Jun N-terminal kinases (JNK1 and JNK2), and p38 MAPK, among which JNK and p38 MAPK promote apoptotic cell death, while ERK1/ERK2 exerts a protective effect [108]. However, the role of JNK MAPKs in apoptosis seems to be contradictory. ROS-dependent activation of JNK/p38 MAPKs has been shown to promote apoptosis [109]. JNK promotes apoptosis through the Bax subfamily of Bcl-2-related proteins [110]. But for ROS-induced apoptosis, JNK activation seems to represent a scavenger pathway for cells, which tries to escape apoptosis [111]. The contradictory role of JNK in apoptosis may lie in the difference in experimental procedures and the metabolic stage of the cells in different experiments [111]. In cardiac myocytes, JNK, ERKs, and p38 MAPK can be activated with the induction of ROS [112-114]. Hori and Nishida thought that apoptosis signal-regulating kinase 1, as an upstream signaling molecule, is activated by ROS, and then activates p38 and JNK, which finally causes apoptosis and cell hypertrophy [95]. The p38 MAPK, primarily related to contribution of apoptosis $[111,115,116]$, is a key signal transduction factor mediating myocardial apoptosis 
following MI/RI [117]. For lung injury, p38 MAPK phosphorylates mitogen-activated protein kinase-activated protein kinase 2 (MK2), contributes the activation of caspase-3, and then leads to apoptosis and cell death [118]. Further study, nevertheless, is needed to determine whether this apoptotic pathway holds in cardiomyocytes. Another report has shown that p38-activated MK2 in MI/RI is detrimental to cardiomyocytes [119]. Although an important role of MK2 in inflammatory response has also been suggested in this literature [119], its regulation of TNF biosynthesis may not be contradictory with the MAPKs/NF- $\kappa \mathrm{B} / \mathrm{TNF}-\alpha$ apoptotic signaling pathway [34] previously mentioned. In the $H / R$ model, p38 MAPK also regulates the accumulation of mitochondrial ROS [6]. TUNEL assay showed that inhibition of p38 kinase activity during hypoxia/reoxygenation prevented H/R-induced apoptosis [120]. On the contrary, activation of ERKs may protect cardiac myocytes from apoptotic death induced by oxidative stress [113]. ERKs also reduce ROS production by inhibiting NOX4 [121]. The dynamic balance between activation of JNK and p38 and activation of ERK may partly determine whether a cell survives or apoptosis [122].

3.1.4. Endoplasmic Reticulum Stress. The ER, under physiological conditions, regulates many biological processes, including protein folding, assembly, modification and secretion, $\mathrm{Ca}^{2+}$ homeostasis, and lipid synthesis [123, 124]. However, when exposed to pathologic conditions, like ROS exposure, $\mathrm{Ca}^{2+}$ overload, deficiency of glucose and nutrient supply, and ATP depletion, homeostasis is impaired with the accumulation of unfolded/misfolded proteins, as described above [87, $88,123]$. RI, impaired autopha/RI, the unfolded protein response and/or ER-initiated apoptosis is likely to be triggered by both the depletion of oxygen and energy substrates and the subsequent sudden increase in oxygen free radicals [125]. It has also been reported that oxidative stress triggered by tissue reperfusion causes $\mathrm{ER} \mathrm{Ca}^{2+}$ depletion, then leading to protein misfolding [126]. MI/RI-activated unfolded protein response upregulates multiple ER stress proteins, including chaperones glucose-regulated protein 78 , activating transcription factor 6 , and transcription factor X-box binding protein-1; many of which act as protective roles, alleviating the ER stress [127]. However, prolonged and/or excessive ER stress-triggered unfolded protein response may cause apoptosis through CHOP and the caspase-12 pathways [87, 90, 127]. CHOP has been known as a key upstream molecule of apoptosis mediated by ER stress. It also downregulates the expression of antiapoptotic Bcl-2 [124].

3.2. Autophagy of Myocardial Cells Induced by ROS. Autophagy is a major pathway for eukaryotic cells to degrade and recycle organelles and macromolecules by which cytosolic long-lived proteins and damaged organelles can be removed [128]. Organelles and macromolecules are sequestrated by double-membrane structures called autophagosomes, delivered to lysosomes, degraded by lysosomal hydrolases, and then recycled $[129,130]$. Different from ischemic autophagy triggered by activation of the AMPK pathway and inhibition of the mTOR pathway [131-133], autophagy during reperfu- sion is upregulated by Beclin 1 dependence [132]. On the contrary, reperfusion is accompanied by inactivation of AMPK [132] and mTOR activation [132, 134], and activated mTOR inhibits autophagy [134-136]. Enhancement of oxidative stress is both necessary and sufficient for causing autophagy in cardiomyocytes RI, impaired autopha/RI [137]. Autophagy can also be induced by $\mathrm{Ca}^{2+}$ overload [138], release of endoplasmic reticulum calcium [130], mitochondrial permeability transition pore (MPTP) opening [139], and CyP-D [140]. As mentioned above, these changes can be caused or enhanced by oxidative stress. Besides, the autophagy is also regulated by components of the apoptosis, including mitochondrial-localized Bcl-2 family members [141]. The antiapoptotic proteins $\mathrm{Bcl}-2$ and $\mathrm{Bcl}-\mathrm{X}_{\mathrm{L}}$ inhibit autophagy through binding and inhibiting Beclin1 [142], while deathinducing Bcl-2 family members, such as Bcl-2 $19 \mathrm{kDa}$ interacting protein 3 or Bax, induce autophagy [141].

Autophagy is characterized by the protection of cell function under normal conditions, whereas autophagy under pathophysiological conditions can either protect against cell damage or serve as another form of programmed cell death, known as PCD type II [143]. Finding out whether autophagy activated respectively during ischemia and reperfusion plays a positive or negative role is important. It is thought that autophagy during acute myocardial ischemia and chronic hibernation is cardioprotective while it is detrimental in myocardial reperfusion after a short period of ischemia $[132,133,144,145]$. Autophagy may itself be a physiological process that protects the heart by removing damaged mitochondria and other organelles and inhibiting ATP depletion. For instance, autophagy is suspected to reduce apoptotic damage via removing damaged mitochondria, thereby limiting the diffusion of proapoptotic factors like apoptosisinducing factor, second mitochondria-derived activator of caspases, and cytochrome c, and reducing ATP depletion [146-149]. It can also repair myocardial cells injured during $\mathrm{H} / \mathrm{R}$ by lysosomal autophagy removal of nonfunctional lysosomes [150]. However, Beclin1-dependent autophagy induced by reperfusion/reoxygenation only promotes autophagosome formation, while autophagosome clearance is impaired, resulting in impaired autophagic flux [151]. Impaired autophagy such as incomplete autophagic removal of damaged mitochondria [152], abnormal lysosome structure and accumulation of autophagic vacuoles [153], loss of lysosomal integrity, and lysosomal proteases released into the cytosol [150] may play a negative role in heart disease. Lysosomal-associated membrane protein 2 (LAMP2) is a key protein for autophagosome-lysosome fusion, and its expression is decreased during $H / R$ injury [151], while BECN1 interferes with autophagosome-lysosome fusion and impairs autophagosome clearance [151, 154]. RI, impaired autopha/RI, impaired autophagosome clearance, which is mediated in part by the ROS-induced decrease of LAMP2 and the upregulation of BECN1 [151, 154, 155], leads to the accumulation of autophagosomes and abnormal clearance of damaged cell components, and finally forms a vicious cycle of increased ROS production and enhanced mitochondrial permeability [154]. Slightly different from the viewpoint of impaired autophagy, it is believed that 
reperfusion can lead to excessive autophagy, which is a cytotoxic effect that leads to excessive degradation and selfdigestion of cellular constituents [136], resulting in irreversible damage and even cardiomyocyte death [132, 156]. In addition, in L929 cells, autophagy is activated by caspase inhibitors, which can lead to catalase degradation, intracellular ROS accumulation, membrane peroxidation, membrane integrity failure, and finally cell death [157].

3.3. Inflammation Triggered by ROS. Oxidative stress and inflammatory response are mutually promoting pathological processes [4, 65, 95]. For example, neutrophils act as one of the sources of ROS, while ROS from endothelial cells and cardiomyocytes amplify inflammatory response and influence nearby neutrophils, inducing a chain reaction of ROS generation [95]. Through the ischemia and reperfusion models of multiple organs, Toll-like receptors have been demonstrated to play an important bridging role in the interaction between oxidative stress and inflammatory response [158]. It is thought that ROS upregulate IL- $1 \beta$ through the NLRP3 inflammasome activation and caspase-1 expression [121]. IL-6 works as a downstream target of IL- $1 \beta$ [159]. It was demonstrated that thioredoxin-interacting proteinmediated NLRP3 inflammasome activation in cardiac microvascular endothelial cells was a novel mechanism of MI/RI [160]. In addition, NF- $\kappa \mathrm{B}$, activated by ROS, regulates the expression of inflammatory genes, like IL- $1 \beta$, IL- 6 , and TNF- $\alpha[161,162]$.

The severe inflammatory conditions during MI/RI have been thought to occur due to the increased cytokines, that is, IL-6, IL- $1 \beta$, and TNF- $\alpha$ [163]. During MI/RI, rapidly increased TNF- $\alpha$ exerts a negative effect via inducing the expression of adhesion molecules and chemokines, promoting the adhesion and interaction of leukocytes with endothelial cells, and increasing leukocyte infiltration $[162,164]$. Similarly, IL-6 and IL-1 $\beta$ aggravate myocardial injury through promoting the adhesion of endothelial cells and neutrophils [162]. Beyond mentioned above, inflammatory factors have been reported to promote platelet adhesion, vascular endothelial injury, collagen exposure, and platelet activation [162]. The inflammatory response triggered by ROS during MI/RI has been reviewed in detail [165]. ROS can directly damage cardiomyocytes or promote cardiomyocyte injury through cytokine release, NF- $\kappa \mathrm{B}$ activation, increase of endothelial cell adhesion molecules, and leukocyte/endothelial cell interaction [165]. Besides, matrix metalloproteinases, activated by ROS and inflammatory cytokines, degrade collagens, then leading to myofibril slippage and left ventricular dilatation [95].

3.4. Other Pathophysiology Caused by ROS. As for oxidative stress-induced MI/RI, there are still other pathological changes that need to be further explored in addition to the frequently studied mechanisms mentioned above. For instance, ROS is believed to be involved in necrotic cardiomyocyte death via MPTP opening that is deemed as a main cause of the necrotic cell death rather than just inducing apoptosis [95]. Another report has shown that in cardiomyocytes, ROS activate NF- $\kappa \mathrm{B}$ and thereby inhibit the Nrf2-
ARE pathway to promote oxidative stress-induced necrosis [166]. In addition to working as signaling molecules in the cell death pathways, ROS also initiate cell death through directly damaging various macromolecules like proteins, DNA, and lipids [67]. As was demonstrated, ROS-mediated reactions with proteins can inactivate key enzymes and ion transporters. With the peroxidation of polyunsaturated fatty acid of cell membranes, the permeability and selectivity of cell membranes to specific ions as well as receptor function alter [165]. Therefore, the effects of ROS on DNA, proteins, and lipids may be just another manifestation of the signaling pathways involved in cardiomyocyte damage. In addition to the above cell injury caused by ROS, NO, along with its product $\mathrm{ONOO}^{-}$, exerts cytotoxic effects that cause cell and tissue damage $[54,56,57]$.

\section{Interventions Targeting Oxidative Stress and Related Pathways in Myocardial Reperfusion}

As mentioned above, based on the multiple sources of ROS, the effects of oxidative stress on MI/RI and the mutual influence of various pathways, it is extremely important to explore multiple targets and systematic intervening measures including traditional Chinese medicine to overcome the limitations of single therapy.

4.1. Antioxidants. It was demonstrated that oxidative stress to cardiomyocyte may lead to detrimental cellular effects like necrosis, apoptosis, or autophagy [22] and elicit MI/RI like arrhythmia, stunning, and infarction [167]. Suppression of OFRs accumulation during MI/RI can alleviate myocardial stunning, irreversible injury, and reperfusion arrhythmias [19]. Many therapeutic strategies have been developed to attenuate MI/RI through counteracting ROS generation and accelerating their consumption.

4.1.1. Inhibition of ROS Generation. Amounts of potential sources of ROS have been researched, such as xanthine oxidase [25], NADPH oxidase (NOX) [26, 27], mitochondria [28], and uncoupled nitric oxide synthase [29]. Different treatments targeting multiple sources of ROS could reduce oxidative stress-induced injury in reperfusion.

(1) Mitochondria. Paraoxonase 2 binds specifically to the complex III in inner mitochondrial membrane, and its deficiency alters mitochondrial function partly by reducing the activities of mitochondrial complexes I/III, thus resulting in the superoxide generation and exacerbating the development of atherosclerosis [168]. A research aiming at exploring the regulatory role of paraoxonase 2 in MI/RI showed that paraoxonase 2 in the myocardium can reduce mitochondrial dysfunction and oxidative stress in cardiomyocytes by activating the PI3K/Akt/GSK-3 RISK pathway [169]. Based on the report that rapid reactivation of complex $\mathrm{I}$, which generates $\mathrm{H}_{2} \mathrm{O}_{2}$ causing oxidative damage and the cell death, is a core pathological mechanism of MI/RI [170], mitochondria-targeted S-nitrosothiol, a mitochondriaselective S-nitrosating agent, can reversibly S-nitrosify complex I to slow the reactivation of mitochondria during the first 
minutes of the reperfusion, thereby decreasing ROS production and oxidative damage [170]. In adult Sprague-Dawley rat MI/RI model, pigment epithelium-derived factor decreased myocardial infarct size during MI/RI, downregulated myocardial apoptosis, improved cardiac function, and increased cardiac functional reserve [171]. The H9c2 myocardial cell hypoxia/reoxygenation (H/R) model was established to further study the protective mechanism of pigment epithelium-derived factor. The results indicate that the protective effect of pigment epithelium-derived factor on MI/RI is realized by inhibiting the production of mitochondrial and cytoplasmic ROS [171]. Dapagliflozin administration during $\mathrm{MI} / \mathrm{RI}$ protects the heart by reducing infarct size, improving left ventricular function, and reducing arrhythmias. The protective effect is achieved in part by reducing mitochondrial ROS production and mitochondrial dysfunction [172].

(2) Xanthine Oxidoreductase. Xanthine oxidase inhibitors, which include purines (allopurinol and oxypurinol) and nonpurines (febuxostat and topiramate), exert antioxidant effects by reducing purine-derived ROS production [173]. In particular, the protective effects of allopurinol administration in MI/RI have been reported, including reduced infarct size, improved ventricular function, and reduced arrhythmia incidence $[25,174-176]$. In a clinical trial examining the cardioprotective effect of oral allopurinol on patients receiving primary percutaneous transluminal coronary angioplasty after acute myocardial infarction, the results showed that allopurinol pretreatment could effectively inhibit the production of oxygen-derived radicals in myocardial reperfusion and restore left ventricular function [177]. Clinical researches showed that allopurinol improved cardiac function and reduced hospital mortality in patients undergoing coronary artery bypass surgery via inhibiting $\mathrm{XO}$-derived ROS generation $[178,179]$.

(3) NOS. As mentioned above, the decreased bioavailability of NO caused by eNOS uncoupling and the cytotoxicity of NO synthesized by iNOS are the cause of myocardial damage induced by NOS. The depletion of tetrahydrobiopterin (BH4), an important cofactor of NOS, in MI/RI resulted in increased eNOS uncoupling and ROS production, but preischemia administration of liposomal $\mathrm{BH} 4$ can reduce the dysfunction of eNOS secondary to BH4 depletion during reperfusion, thus protecting cardiac function [180]. To investigate the effect of quercetin on the expression of NOX2, eNOS, and iNOS genes and proteins in the rabbit heart after myocardial ischemia/reperfusion injury, a MI/RI model was established in New Zealand white rabbits by myocardial ischemia for $30 \mathrm{~min}$ and reperfusion for $12 \mathrm{~h}$. The results indicate that quercetin can not only inhibit MI/RI-induced expression of NOX2 and iNOS but also eNOS [181]. The protection to the myocardium by inhibiting eNOS expression may be due to the reduction of iNOS induction and decreased iNOS-derived peroxynitrite during late reperfusion, which is in contradiction with the positive effect of eNOS during early reperfusion [182]. Insulin [183] and pterostilbene [108] can not only increase the phosphorylation of eNOS, promoting the production of physiological NO and the reduction of superoxide, but also inhibit the expression of iNOS. It was shown that insulin and pterostilbene protected against $\mathrm{MI} / \mathrm{RI}$ by blocking $\mathrm{ONOO}^{-}$-triggered oxidative/nitrative stress and that they both improved cardiac functions, as well as reduced myocardial infarction, apoptosis, and creatine kinase/lactate dehydrogenase release. Studies have shown that the exogenous donor of NO, NOaspirin, releases $\mathrm{NO}$ at a rate similar to the endogenous NO derived from L-arginine, which limits infarct size, improves myocardial contractile dysfunction, and reduces the mortality rate, during MI/RI [184]. In addition, due to the antiplatelet aggregation and vasodilation effects of $\mathrm{NO}$ [184], it may reduce microvascular obstruction following reperfusion. Similar therapeutic effects may be achieved through microbubble oscillations, which can increase blood perfusion through activating the eNOS pathway and releasing NO [185].

(4) NAD $(P) H$ Oxidase. The NOX family of NADPH oxidase may produce superoxide and other ROS by transporting electrons through the biological membranes from NADPH to $\mathrm{O}_{2}$ during MI/RI, especially NOX2 and NOX4 [64]. Injection with $\mathrm{H}_{2} \mathrm{O}_{2}$-responsive antioxidant PVAX nanoparticles was used to evaluate the therapeutic effect of PVAX on MI/RI in mice. The results of dihydroethidium staining showed that PVAX effectively inhibited MI/RI-caused ROS production, and PVAX targeted the production site of ROS, reducing the expression levels of NOX2 and NOX4 that are the main NOX subtypes in the heart, thus protecting against MI/RI [23]. By suppressing the PKC-6/NOX2 /ROS signaling pathways in H9c2 cells, Wenxin Granule, a Chinese patent medicine commonly used in cardiovascular diseases, inhibits oxidative stress, mitochondrial dysfunction, and myocardial cell apoptosis induced by H/R [186]. In addition, as has been demonstrated, cardiotonic pill that is a compound Chinese medicine used in the treatment of ischemic angina pectoris can achieve antioxidative effect by inhibiting NADPH oxidase activation, thus reducing MI/RI-caused rat myocardial injury and microcirculatory disturbance [187].

4.1.2. Endogenous Antioxidant Systems. The endogenous antioxidant systems can protect cells against the potential injury through regulating the balance of individual ROS and their reactants, maintaining "redox homeostasis" [35]. Major endogenous antioxidants in cardiomyocytes include superoxide dismutase (SOD), catalase (CAT), glutathione peroxidase (GSH-Px), glutathione, coenzyme Q10 (ubiquinone), and vitamins $\mathrm{C}$ and $\mathrm{E}$ [35]. Some interventions enhance the activity of endogenous antioxidant systems. Cheng et al. evaluated the cardiac protective effect of $\mathrm{N}$ propyl caffeamide, a newly synthesized caffeic acid derivative, on a mouse MI/RI model. The results showed that N-propyl caffeamide effectively reduced infarct size and the release of myocardial enzymes such as creatine kinase, creatine kinase isoenzyme, and lactate dehydrogenase. Biochemical analysis showed that N-propyl caffeamide increased the activity of antioxidant enzymes (such as CAT and SOD) while decreased the lipid peroxidation [188]. In a research to investigate the effects of galectin-3 on MI/RI, C57B6/J wild-type 
(WT) mice and galectin-3 knockout (KO) mice were used to establish murine model with MI/RI for $30 \mathrm{~min}$ of ischemia and $24 \mathrm{~h}$ of reperfusion. The results showed that troponin I in the galectin-3-KO group was significantly higher than that in the wild-type group, along with reduced SOD, GSH, and CAT and enhanced apoptotic activity [189]. Besides, trans sodium crocetinate was shown to upregulate sirtuin 3 expression and subsequently regulate the posttranslational protein modification of FOXO3a, thereby increasing SOD2 protein level and alleviating MI/RI-induced myocardial oxidative stress [190]. Silent information regulator 1 (SIRT1) can deacetylate and activate FOXO that synthesizes antioxidants such as manganese superoxide dismutase (MnSOD) and catalase [191, 192]. Berberine may target SIRT1 to protect against MI/RI induced by oxidative stress [193]. An in vitro MI/RI study showed that scutellarin, a flavone extracted from traditional Chinese medicine, could inhibit oxidative stress by increasing SOD concentration, thus protecting cardiomyocytes [194]. Intravenous administration of watersoluble acacetin prodrug could improve ventricular arrhythmias, infarct size, and cardiac dysfunction, which were induced by MI/RI in rats. Molecular mechanisms suggested that its protective effect on the myocardium was achieved partly by preventing the reduction of endogenous antioxidants such as SOD2 and thioredoxin [195]. A clinical research of 34 patients showed that human recombinant SOD alleviated reperfusion arrhythmias, but did not significantly improve left ventricular function. This may be due to the fact that the myocardial cell damage during reperfusion is not caused by superoxide but by other ROS, or that SOD in the damaged myocardium does not reach the effective concentration during reperfusion [196]. Another clinical report has shown that $\mathrm{N}$-acetylcysteine, a precursor of glutathione, limits infarct size, reduces reperfusion ventricular arrhythmias, improves global and regional left ventricular function, and normalizes electrocardiogram [197]. In addition, there is evidence that preoperative upregulation of antioxidant enzymes and nonenzymatic antioxidants may reduce the incidence of postoperative atrial fibrillation [22].

4.1.3. Exogenous Antioxidants. Since endogenous antioxidant levels are not sufficient to prevent reperfusion injury [198], it is also important to explore more exogenous antioxidants. Pretreatment for the hearts with $\mathrm{N}$-acetylcysteine and $\mathrm{N}$ mercaptopropionylglycine that are exogenous antioxidants has been shown to be beneficial in preventing MI/RI, but further studies are needed to determine their effectiveness in reversing MI/RI-induced abnormalities in the heart [199]. Tong et al. used in vitro $\mathrm{H} / \mathrm{R}$ cell model and in vivo local MI/RI mouse models to explore the effects of intravenous administration of lycopene on ROS during MI/RI. It suggested that intravenous administration of lycopene could protect mice from MI/RI by inhibition of ROS accumulation [200]. It was reported that novel pyridoindole derivatives seemed to inhibit the incidence of reperfusion injury like ventricular tachycardia and ventricular fibrillation in MI/RI through antioxidation and free radical scavenging protection. In addition, SMe1EC2, one of the pyridoindole derivatives, promotes recovery of the left ventricular function, such as decreasing left ventricular end-diastolic pressure and recovery of the stunned myocardium [201]. Besides, probucol, a lipophilic antioxidant, has been reported to reduce myocardial stunning during reperfusion following short-term ischemia in the rabbit [202].

\subsubsection{Mitochondria-Targeted ROS Scavengers. Antioxidants} that are neither targeted nor accumulated in the mitochondria may be ineffective [10]. Mitochondria are deemed the major intracardiac source of ROS during MI/RI [35]. Mitochondria-targeted ROS scavengers may be more effective and more easily controlled than general antioxidants. MitoQ [203, 204], a mitochondria-targeted antioxidant containing the antioxidant quinone moiety, can be concentrated by the lipophilic triphenylphosphonium cation for several hundredfold within mitochondria, protecting the cardiomyocytes from MI/RI. Mitochondria-targeted Szeto-Schiller peptides (SS peptides) can decrease mitochondrial ROS generation, prevent mitochondrial permeability transition, inhibit cytochrome $c$ release, reduce lipid peroxidation, limit the infarct size, prevent reperfusion ventricular arrhythmias, restore myocardial contraction, and prevent reperfusionrelated myocardial stunning $[205,206]$. Treatment of irisin, a muscle-origin protein, reduces infarct size, improves left ventricular ejection fraction, decreases serum troponin I, and inhibits apoptosis during MI/RI by regulating mitochondrial localization of SOD2 and increasing SOD2 activity [207]. Furthermore, since rapid reoxidation of succinate by succinic dehydrogenase may lead to massive ROS generation and cardiomyocyte death during reperfusion [208], inhibition of succinic dehydrogenase by malonate limits infarct size via alleviating ROS generation in the isolated mouse hearts during reperfusion period [208].

\subsubsection{Regulation of the Oxidation Defense System}

(1) Nuclear Factor Erythroid-Related Factor 2 (Nrf2). Nrf2, a nuclear transcription factor, plays an indispensable regulatory role in the defensive genes that encode detoxifying enzymes and antioxidant proteins, contributing to cellular resistance to oxidants $[209,210]$ and it is involved in inducing endogenous antioxidant enzymes to respond to oxidative stress [211]. Nrf2 binds to its cytosolic repressor Kelch-like $\mathrm{ECH}$-associated protein 1 under nonoxidative stress and is ultimately targeted for ubiquitination and proteasomal degradation. However, Nrf2 dissociates from Kelch-like ECHassociated protein 1 and migrates to the nucleus under the influence of ROS. After binding to antioxidant response elements (AREs), Nrf2 promotes the expression of antioxidant genes and produces enzymes related to antioxidant defense, such as glutathione reductase (GR), heme oxygenase 1 (HO-1), and superoxide dismutase 1 (SOD1) [18, 209, 210, 212]. HO-1, an intracellular inducible phase II detoxifying enzyme, can be regulated by Nrf2 [213]. The Nrf2/HO-1 signaling pathway is related to defense against a variety of oxidative-inducing agents and represents a promising target for inhibiting MI/RI [213]. Many drugs or extracts thereof, such as resveratrol [211] and triptolide [214], inhibit oxidative stress by activating the $\mathrm{Nrf} 2 / \mathrm{HO}-1$ signal, thereby 
limiting infarct size and improving cardiac function. Preconditioning with Potentilla reptans L. root can exert cardioprotective and antiapoptotic effects through NO release, the Nrf2 pathway, and endogenous antioxidant activity, thereby alleviating arrhythmias and infarct size, and improving myocardial stunning [215]. Upstream signaling molecules of Nrf2 can also serve as targets for MI/RI therapies, such as phosphatidylinositol-3-kinase (PI3K) [216, 217], protein kinase C (PKC) [217], and silent information regulator 1(SIRT1) [218]. Glycogen synthase kinase 3 (GSK3) [219-221], which promotes degradation and inactivation of Nrf2, is also a therapeutic target. For instance, Shanmugam et al. used the Langendorff isolated heart perfusion system to research the myocardial protective effect of fisetin, a natural flavonoid, on MI/RI. The results suggested that fisetin could induce the expression of Nrf-1/2 through inhibiting GSK-3, thereby synthesizing HO-1, SOD, and GR, clearing ROS, and finally inhibiting apoptosis [222].

(2) Hypoxia-Inducible Factor-1 (HIF-1). HIF-1 is a critical regulator of the transcriptional response to hypoxia conditions of mammalian cells [223]. Evidences suggested that HIF-1 expression is increased after myocardial ischemia $[224,225]$ and that HIF-1 is also activated by ROS [226, 227]. HIF-1 protects the myocardium from reperfusion injury. For example, HIF- $1 \alpha$ mediates ischemic preconditioning $[18,228]$, regulating HO- 1 , and eNOS expressing [18], which, as described previously, alleviate MI/RI-induced oxidative stress. HIF-1 is regulated by PI3K/Akt. For instance, troxerutin alleviates oxidative stress in $\mathrm{H} 9 \mathrm{c} 2$ cardiomyocytes through activation of the PI3K/Akt/HIF- $1 \alpha$ signaling pathway [229]. Besides, the antioxidants $\mathrm{N}$ acetylcysteine and allopurinol combat MI/RI synergistically in diabetes primarily restore through the HIF- $1 \alpha / \mathrm{HO}-1$ signaling pathway [230].

(3) PI3K/Akt. Activation of phosphatidylinositol-3-kinase (PI3Ks) and its downstream target protein kinase B (Akt) regulates myocardial oxidative stress and promotes myocardial protection against MI/RI [231]. The regulatory effect of insulin on NOS mentioned above may be realized through the PI3K/Akt-dependent pathway [183]. GSK-3, which promotes MPTP [134], inhibits activation of mTOR [134], and promotes Nrf2 degradation [219-221], is inactivated by Akt phosphorylation [232]. Pretreatment with hydroxytyrosol seems to reduce myocardial infarct size, decrease apoptosis, and improve cardiac systolic function through this signaling pathway during MI/RI [233]. In addition, Akt acts on cytoplasmic peptide $\mathrm{Bad}$ (Bcl-2 family proteins), which is isolated in the cytoplasm, and inhibits apoptosis [232]. Signaling molecules that regulate the PI3K/Akt pathway can be used as targets for antioxidative stress. For example, phosphatase PTEN that negatively regulates the PI3K/Akt pathway can be inhibited by ROS [234, 235], exosomes derived from bone marrow stromal cells [236], or Achyranthes bidentata polypeptides [237], then enhancing Akt phosphorylation and promoting myocardial protection. Treatments targeting PI3K/Akt or related signaling pathways reduce reperfusion complications such as arrhythmias [238, 239], myocardial stunning [239], myocardial no-reflow [240], and adverse remodeling [241].

\subsection{Regulation of Apoptosis-Related Pathways}

4.2.1. Regulation of $\mathrm{Ca}^{2+}$ Overloading. Intracellular $\mathrm{Ca}^{2+}$ overload, as mentioned above, can be triggered by ROS in a variety of ways $[19,91-94]$. Apart from inducing MPTP opening, $\mathrm{Ca}^{2+}$ overload in cardiomyocytes also leads to cell death by causing excessive contraction of cardiomyocytes during reperfusion [5]. Therefore, the exploration of strategies to inhibit $\mathrm{Ca}^{2+}$ overload may provide new ideas for the prevention and treatment of oxidative stress-induced reperfusion injury. For example, intracardiac injection of 4(RS)4-F4t-neuroprostane before ischemia, a nonenzymatic oxidized metabolite of cardiac protective docosahexaenoic acid, can limit myocardial infarction and reduce the incidence of ventricular arrhythmias [242]. The results not only showed the protective effect of 4(RS)-4-F4t-neuroprostane against mitochondrial $\mathrm{Ca}^{2+}$ overload, which is related to decreased MPTP opening, but also suggest that its antiarrhythmic properties seem related to reduced $\mathrm{Ca}^{2+}$ release from sarcoplasmic reticulum, diastolic membrane hyperpolarization, and action potentials shortening [242]. Tetramethylpyrazine, an alkaloid extracted from the traditional Chinese medicine Ligusticum chuanxiong Hort, protects against MI/RI by preventing $\mathrm{Ca}^{2+}$ overload and scavenging OFRs, among other beneficial pathways [243]. Mitochondrial ATP-sensitive potassium channel $\left(\right.$ mitoK $\left._{\mathrm{ATP}}\right)$ can reduce mitochondrial $\mathrm{Ca}^{2+}$ overload, increase ATP synthesis, and increase protective ROS production during preconditioning but decrease ROS generation during reperfusion [244, 245]. Activation of mitochondrial potassium channels partly protects against reperfusion injury by a mild depolarization and reduction of $\mathrm{Ca}^{2+}$ accumulation in the matrix, then reducing MPTP opening and apoptosis [246]. The novel $\mathrm{H}_{2} \mathrm{~S}$ donor 4-carboxyphenyl isothiocyanate can prevent $\mathrm{Ca}^{2+}$ accumulation in the mitochondrial matrix, and the mitoK $_{\text {ATP }}$ may be a relevant pharmacological target of it [247]. Regulation of $\mathrm{Ca}^{2+}$ has been reported to ameliorate complications associated with MI/RI. In a model simulating MI/RI, Salvia miltiorrhiza was showed to improve antioxidant and calcium regulation in cardiomyocytes during MI/RI and reduce arrhythmias and apoptosis [248]. In a porcine model of MI/RI, sarcoplasmic reticulum $\mathrm{Ca}^{2+}$ ATPase pump improves mechanical and electric stability in the heart through reducing $\mathrm{Ca}^{2+}$ overload and then inhibits ventricular arrhythmias [249]. In addition, calcium regulation can reduce myocardial death and heart failure [250].

4.2.2. Regulation of MPTP Opening. Mitochondria-mediated apoptosis is recognized as a key part in MI/RI [251]. During reperfusion, $\mathrm{Ca}^{2+}$ overload and excessive ROS production, along with some other factors, can trigger MPTP opening [252]. Myocardial ischemia/reperfusion injury mainly depends on the opening of MPTP within the first few minutes of reperfusion and subsequent mitochondrial dysfunction [253, 254]. MPTP contributes $50 \%$ to MI size [253]. It has been reported [254] that ischemic 
preconditioning and ischemic postconditioning may inhibit MPTP formation by regulating calcium balance, oxidative stress, ATP level, and $\mathrm{pH}$ recovery, as well as direct MPTP inhibition involving the complex signal transduction pathways, thus exploring more targets for the treatments of myocardial reperfusion injury. In the rat MI/RI models established by ligation of the left coronary artery (30 min) and reperfusion (120 $\mathrm{min})$, pretreatment of 3-methyl-1-phenyl-2-pyrazolin-5-one, a free radical scavenger, can inhibit intracellular $\mathrm{Ca}^{2+}$ overload caused by oxidative stress, thereby inhibiting MPTP opening [198]. In addition, mitochondrial swelling, the release of cytochrome $c$, and myocardial cell apoptosis can be reduced by 3-methyl-1-phenyl-2pyrazolin-5-one through inhibiting MPTP opening [198]. Schaffer et al. have comprehensively reviewed the protective effects of taurine in MI/RI, which suppresses MPTP activation by inhibiting calcium overload, reducing ROS overproduction in respiratory chain, and activating the Aktdependent protective signaling pathway [255]. It has been reported with heart protection during bypass surgery, heart transplantation, and myocardial infarction, and severe loss of it may increase the risk of reperfusion ventricular remodeling and heart failure [255]. Inhibition of MPTP during reperfusion was also showed to promote functional recovery and reduce mortality in mice [256]. Besides, matrix CyP-D promotes MPTP opening by enhancing its calcium sensitivity [102], and CyP-D serves as a target for cyclosporin A to protect cardiomyocytes [18]. However, Bennett and Norman described toxicity of cyclosporine [104]. Newer CyP-D inhibitors such as hematopoietic-substrate-1-associated protein X-1 [98] and polylactic/glycolic acid nanoparticles [257] may overcome the shortcoming of CsA. Cardio-specific hematopoietic-substrate-1-associated protein X-1 downregulates cyclophilin $\mathrm{D}$ levels through interfering its binding to heat shock protein-90 [98], rather than involving CsA. Polylactic/glycolic acid nanoparticles regulate the in vivo kinetics of CsA by selective delivery to the MI/RI-related cardiomyocyte cytosol and mitochondria [257], and treatment with nanoparticles incorporated with CsA enhanced the cardioprotection of CsA, even at low CsA concentrations [257], which may effectively reduce the toxicity of CsA. In addition, increased acetylation of CyP-D after myocardial reperfusion promotes MPTP opening, and ischemic postconditioning may promote deacetylation of CyP-D and prevent MPTP opening by increasing sirtuin 3 activity which prevent lethal reperfusion injury [258].

4.2.3. Regulation of Bcl-2 Family Proteins. ROS triggers the initiation of apoptosis, which is related to the decrease of antiapoptotic $\mathrm{Bcl}-2$ and proapoptotic Bax ratio during MI/RI [259]. The ratio of Bcl-2 to Bax can decide whether cell survives or not following apoptotic stimulation [260]. Therefore, the exploration of therapeutic strategies regulating the expression of $\mathrm{Bcl}-2$ and Bax may provide new targets against oxidative stress. For example, the cardiac protective effect of $\mathrm{N}$-propyl caffeamide is not only realized by regulating the activity of CAT and SOD as mentioned above but also by upregulating the expression of $\mathrm{Bcl}-2$ in myocardial tissue and inhibiting the expression of Bax [188]. In addition, it has been reported that treatment with diltiazem plus SOD during MI/RI in a rat model can inhibit the apoptosis pathway, and that one of the results showed increased Bcl-2 expression and decreased Bax expression [261]. The phenylethanoid glycoside-rich extract of Cistanche deserticola reduces oxidative stress in the reperfusion myocardium and plays an important role in suppressing apoptosis pathways. Results of the research also included upregulation in the ratio of Bcl-2 to Bax [262]. It has been shown that adrenomedullin can protect against MI/RI-induced myocardial infarction, arrhythmias, and apoptosis by activating NO/cGMP to inhibit ROS-induced phosphorylation of Bax and p38 MAPK and activation of the Akt-Bad-Bcl-2 signaling pathway [263].

4.2.4. Regulation of MAPK Family. Activated by ROS, MAPKs (mainly p38 and JNK MAPKs) initiate exogenous cell death cascades through the MAPK/NF- $\kappa \mathrm{B} / \mathrm{TNF}-\alpha$ signaling pathway. Interventions targeting p38 MAPK or JNK have been shown to protect against oxidative stress-induced MI/RI. Dual-specificity phosphatase is upregulated by $\mathrm{N}$ acetylcysteine pretreatment [120]. And the modulation of p38 MAPK by dual-specificity phosphatase is indispensable to improve cardiovascular function under oxidative stress [120]. Betulinic acid protects H9c2 cells from MI/RI by inhibiting oxidative stress and apoptosis, and the Nrf2/HO-1, JNK, and p38 pathways are involved in mediating these protective effects [264]. Syringic acid, a natural O-methylated trihydroxybenzoic acid monomer that is extracted from Dendrobium nobile Lindl., protects $\mathrm{H} 9 \mathrm{c} 2$ cardiomyocytes from $\mathrm{H} / \mathrm{R}$-induced apoptotic injury via inhibiting the activation of the p38 MAPK and JNK signaling pathways [265]. Injection of snakegourd peel, a traditional Chinese herbal medicine, inhibits the apoptosis of myocardial cells by reducing intracellular $\mathrm{Ca}^{2+}$ overload, inhibiting the activation of caspase- 3 , and downregulating the phosphorylated JNK (p-JNK) and p38 MAPK (p-p38 MAPK) protein expression [266].

4.2.5. Regulation of Endoplasmic Reticulum Stress. During $\mathrm{MI} / \mathrm{RI}$, prolonged or excessive ER stress triggered by oxidative stress and other causes acts as a target for intervening in oxidative stress-induced reperfusion injury; in that, it causes apoptosis of the cardiomyocytes. Transforming growth factor $\beta$-activated protein kinase 1 , a key regulator of cell death, may trigger MI/RI as an upstream signaling molecule of the ROS/ER stress pathway, and inhibition of it significantly decreased MI/RI-induced infarct size, reduced cell death, and improved cardiac function [87]. It has been reported that prevention of the ER stress with two chemical chaperones, tauroursodeoxycholic acid and 4-phenylbutyric acid, could limit the deterioration of the contractile function in the stunned myocardium such as reperfusion following acute myocardial infarction [88]. In vitro and in vivo experiments have shown that sulodexide pretreatment [267] and tournefolic acid B [268] may exert inhibiting role in ER stress through the PI3K/Akt pathway and then inhibit cell apoptosis. Silibinin treatment has been reported to improve cardiac function, reduce infarct size, and inhibit fibrotic remodeling in $\mathrm{MI} / \mathrm{RI}$ mice. Its protective effect was achieved partly by inhibiting ER stress [90]. Shuxuening injection, an extract of Ginkgo 
biloba, protects against MI/RI mainly by preventing oxidative stress and ER stress, thus regulating the Toll-like receptor $4 / \mathrm{NF}-\kappa \mathrm{B}$ pathway so as to reduce inflammation, and inhibiting procoagulant-related factors to reduce thrombosis [162].

4.3. Regulation of Autophagy-Related Pathways. The decline of LAMP2 and upregulation of BECN1 mediate the damage of autophagosome clearance during MI/RI, forming a vicious cycle of increased ROS production and enhanced mitochondrial permeability, which eventually leads to cell death [151, 154, 155]. Therapeutic measures targeting BECN1 or LAMP2 expression may reduce oxidative stress-induced reperfusion injury, such as partial BECN1 knockdown [154], inhibition of BECN1 expression by urocortin [269], and upregulating LAMP2 by exogenous calreticulin postconditioning [270]. There are other therapies that do not rely on Beclin1 and LAMP2 to restore impaired autophagy. For example, sustain-releasing $\mathrm{H}_{2} \mathrm{~S}$ donor 5-(4-methoxyphenyl)-3H-1, 2dithiole-3-thione [155], metformin [271], and sevoflurane precondition [272] restore the impaired autophagic flux induced by MI/RI through AMPK activation, thus protecting the myocardium from MI/RI. Intermittent fasting [273] and cilostazol [274] protect against myocardial ischemia/reperfusion injury by transcription factor EB-mediated transcriptional initiation of autophagy-lysosome mechanisms. Transient hypoxia can also protect against reperfusion injury by slightly upregulating autophagy [275]. In a MI/RI model with female farm pigs, myocardial hypothermia was shown to prevent myocardial remodeling through increasing autophagic flux and mitophagy [276]. Since excessive autophagy caused by MI/RI leads to cytotoxic effects with excessive degradation of cellular components and self-digestion, prevention of excessive autophagy caused by MI/RI may play a protective role in the heart. For example, PI3K/Akt upregulates mTOR expression, promotes downregulation of autophagy, and protects myocardial reperfusion injury [136]. Trimetazidine inhibits excessive autophagy induced by MI/RI by activating the Akt/mTOR pathway, which protects the rat hearts from heart failure, reduces infarct size, and so on [136]. Sevoflurane postcondition protects the rat heart from MI/RI by inhibiting autophagy overactivation and promoting autophagosome clearance [277]. Phellinus linteus mycelium pretreatment was used to significantly reduce MI/RI-induced myocardial infarct size, lactate dehydrogenase level, ventricular arrhythmias, and mortality in part by enhancing protective autophagy and inhibiting excessive autophagy [278].

4.4. Regulation of Inflammatory Response. The nuclear transcription factor- $\kappa \mathrm{B}$ may be an ideal target for the treatments against reperfusion injury; in that, it plays an important role in cardiomyocyte apoptosis and inflammatory injury triggered by oxidative stress during MI/RI. Apart from inhibition of ER stress, silibinin also exerts cardioprotective effect against MI/RI through alleviating inflammatory response via deactivating the NF- $\kappa$ B pathway [90]. Researches show that microRNA-130a-5p targeted high mobility group box 2 to downregulate the NF- $\kappa \mathrm{B}$ to relieve the MI/RI-induced inflammatory injury [279]. Cytokines such as TNF- $\alpha$, IL-6, and IL- $1 \beta$ are also indispensable in ROS-induced inflammatory injury. Dietary selenium intake, for example, reduces myocardial infarct size of rats and reduces adverse remodeling, and beneficial effect of it might be partly related to the inhibition of proinflammatory cytokine overexpression [280]. The supplementation of phyllanthin, a major bioactive lignin compound from Phyllanthus species, has also been reported to diminish IL- 6 , IL- $1 \beta$, and TNF- $\alpha$ in the mice during MI/RI, as well as suppress the overexpression of NF- $\kappa$ B [163]. In addition, interventions acting on inhibiting NLRP3 inflammasome activation may be deemed as novel therapies for relieving MI/RI [160].

\section{Conclusion}

Reperfusion following myocardial ischemia may lead to accelerated myocardial injury and worsening clinical outcomes. One of the most important pathological mechanisms in reperfusion injury is oxidative stress, which is the imbalance between the antioxidant system and the excessive production of ROS, leading to the toxic accumulation of reactive oxygen intermediates.

Multiple sources of ROS have been reported, including electron leakage from the ETC in mitochondria, the conversion of hypoxanthine and xanthine to uric acid catalyzed by xanthine oxidoreductase, "being uncoupled" of NOS to their primary role of NO synthesis, the transfer of electrons from $\mathrm{NADPH}$ catalyzed by NADPH oxidase, and other sources like the monoamine oxidases, lipoxygenases, cyclooxygenases, cytochrome P450, neutrophils, and catecholamine.

ROS mainly cause cardiomyocyte death through apoptotic pathway, autophagic pathway, inflammatory pathway, and cytotoxic effect. On the one hand, ROS initiate one apoptotic pathway through $\mathrm{Ca}^{2+}$ overload and decreased ratio of Bcl-2 to Bax, then formation of MPTP, mitochondrial membrane potential collapse, release of apoptotic signaling molecules, and finally activation of caspase-3. On the other hand, ROS initiate exogenous apoptotic pathway by activating MAPK family, upregulating activated NF- $\kappa \mathrm{B}$, promoting the synthesis and release of TNF- $\alpha$, binding of TNF- $\alpha$ to membrane surface receptors, and activating caspase- 8 and caspase-3. Besides, ROS trigger ER-related apoptosis with the increased expression of CHOP and the activation of caspase-12. As for autophagic pathway, ROS induce decrease of LAMP2 and upregulation of BECN1, leading to impaired autophagic flux and excessive autophagy. About inflammation, ROS lead to pathological injury through inflammatory response with cytokine release, NF- $\kappa \mathrm{B}$ activation, increased adhesion molecules, and leukocyte/endothelial cell interaction. The inflammatory response also induces MMPs activation, then leading to collagen degradation, myofibril slippage, and left ventricular dilatation. Finally, NO synthesized by iNOS and $\mathrm{ONOO}^{-}$produced by $\mathrm{NO}$ and $\mathrm{O}_{2}^{-}$cause cardiomyocyte death through cytotoxicity.

Fortunately, some interventions are currently available for ROS-induced reperfusion injury, including antioxidant therapy, along with regulation of apoptosis-related pathways, autophagy-related pathways, and inflammatory response. Researches have shown that these interventions 
can reduce reperfusion-mediated complications such as remodeling, arrhythmias, myocardial stunning, microvascular obstruction, and heart failure to a certain extent, as well as reduce mortality.

However, researches on the mechanisms of reperfusion injury caused by oxidative stress still need to be further improved, and more measures targeting various pathways and targets need to be explored. In addition, many of the current studies are based on animal or molecular level while fewer clinical studies have been done. Therefore, in future studies, (i) it may be of additional value to develop a comprehensive understanding of the oxidative stress involved in $\mathrm{MI} / \mathrm{RI}$ and its associated signaling pathways, thereby reducing the risk of exposure. (ii) In terms of treatments, in addition to antioxidant therapies, systematic interventions targeting various pathways may overcome the limitations of single measures and targets. (iii) In addition to more abundant and mature laboratory research, more clinical research should be performed appropriately.

\section{Disclosure}

The first author is Mi Xiang and the co-first authors are Yingdong Lu and Laiyun Xin.

\section{Conflicts of Interest}

The authors declare that they do not have anything to disclose regarding conflict of interest with respect to this manuscript.

\section{Authors' Contributions}

Mi Xiang wrote the main text. Yingdong Lu and Laiyun Xin contributed equally to this work. Chang Shang, Zhilin Jiang, Hongchen Lin, et al. retrieve and organize the documents. Xiangning Cui and Mingjing Zhao had great contribution in second time revision, polishing manuscript, and helping in revising figures.

\section{Acknowledgments}

We thank Y.D. Lu, M.J. Zhao, and X.N. Cui for the guidance and revision of this manuscript. This work was funded by grants from the National Natural Science Foundation of China (No. 81973842).

\section{References}

[1] H. Y. Chen, Z. Z. Xiao, X. Ling, R. N. Xu, P. Zhu, and S. Y. Zheng, "ELAVL1 is transcriptionally activated by FOXC1 and promotes ferroptosis in myocardial ischemia/reperfusion injury by regulating autophagy," Molecular Medicine, vol. 27, no. 1, p. $14,2021$.

[2] N. Schanze, C. Bode, and D. Duerschmied, "Platelet contributions to myocardial ischemia/reperfusion injury," Frontiers in Immunology, vol. 10, p. 1260, 2019.

[3] A. L. Moens, M. J. Claeys, J. P. Timmermans, and C. J. Vrints, "Myocardial ischemia/reperfusion-injury, a clinical view on a complex pathophysiological process," International Journal of Cardiology, vol. 100, no. 2, pp. 179-190, 2005.
[4] M. Neri, V. Fineschi, M. Di Paolo et al., "Cardiac oxidative stress and inflammatory cytokines response after myocardial infarction," Current Vascular Pharmacology, vol. 13, no. 1, pp. 26-36, 2015.

[5] D. M. Yellon and D. J. Hausenloy, "Myocardial reperfusion injury," New England Journal of Medicine, vol. 357, no. 11, pp. 1121-1135, 2007.

[6] M. I. Ashraf, M. Ebner, C. Wallner et al., “A p38MAPK/MK2 signaling pathway leading to redox stress, cell death and ischemia/reperfusion injury," Cell Communication and Signaling: CCS, vol. 12, no. 1, p. 6, 2014.

[7] S. Hernandez-Resendiz, K. Chinda, S. B. Ong, H. CabreraFuentes, C. Zazueta, and D. J. Hausenloy, "The role of redox dysregulation in the inflammatory response to acute myocardial ischaemia-reperfusion injury-adding fuel to the fire," Current Medicinal Chemistry, vol. 25, no. 11, pp. 12751293, 2018.

[8] H. Zhou, J. Wang, P. Zhu, S. Hu, and J. Ren, "Ripk3 regulates cardiac microvascular reperfusion injury: the role of IP3Rdependent calcium overload, $\mathrm{XO}$-mediated oxidative stress and F-action/filopodia-based cellular migration," Cellular Signalling, vol. 45, pp. 12-22, 2018.

[9] M. Yang, B. S. Linn, Y. Zhang, and J. Ren, "Mitophagy and mitochondrial integrity in cardiac ischemia-reperfusion injury," Biochimica et Biophysica Acta (BBA) - Molecular Basis of Disease, vol. 1865, no. 9, pp. 2293-2302, 2019.

[10] K. Raedschelders, D. M. Ansley, and D. D. Chen, "The cellular and molecular origin of reactive oxygen species generation during myocardial ischemia and reperfusion," Pharmacology \& Therapeutics, vol. 133, no. 2, pp. 230-255, 2012.

[11] E. M. Boyle Jr., T. G. Canty Jr., E. N. Morgan, W. Yun, T. H. Pohlman, and E. D. Verrier, "Treating myocardial ischemiareperfusion injury by targeting endothelial cell transcription," The Annals of Thoracic Surgery, vol. 68, no. 5, pp. 1949-1953, 1999.

[12] J. G. Farías, V. M. Molina, R. A. Carrasco et al., “Antioxidant therapeutic strategies for cardiovascular conditions associated with oxidative stress," Nutrients, vol. 9, no. 9, p. 966, 2017.

[13] T. L. Vanden Hoek, C. Li, Z. Shao, P. T. Schumacker, and L. B. Becker, "Significant levels of oxidants are generated by isolated cardiomyocytes during ischemia prior to reperfusion," Journal of Molecular and Cellular Cardiology, vol. 29, no. 9, pp. 2571-2583, 1997.

[14] L. G. Kevin, A. K. Camara, M. L. Riess, E. Novalija, and D. F. Stowe, "Ischemic preconditioning alters real-time measure of $\mathrm{O}_{2}$ radicals in intact hearts with ischemia and reperfusion," American Journal of Physiology-Heart and Circulatory Physiology, vol. 284, no. 2, pp. H566-H574, 2003.

[15] L. G. Kevin, E. Novalija, M. L. Riess, A. K. Camara, S. S. Rhodes, and D. F. Stowe, "Sevoflurane exposure generates superoxide but leads to decreased superoxide during ischemia and reperfusion in isolated hearts," Anesthesia \& Analgesia, vol. 96, no. 4, pp. 949-55, table of contents, 2003.

[16] J. L. Zweier, B. K. Rayburn, J. T. Flaherty, and M. L. Weisfeldt, "Recombinant superoxide dismutase reduces oxygen free radical concentrations in reperfused myocardium," Journal of Clinical Investigation, vol. 80, no. 6, pp. 1728-1734, 1987.

[17] K. Berg, P. Jynge, K. Bjerve, S. Skarra, S. Basu, and R. Wiseth, "Oxidative stress and inflammatory response during and following coronary interventions for acute myocardial infarction," Free Radical Research, vol. 39, no. 6, pp. 629-636, 2005. 
[18] S. Cadenas, "ROS and redox signaling in myocardial ischemia-reperfusion injury and cardioprotection," Free Radical Biology and Medicine, vol. 117, pp. 76-89, 2018.

[19] J. I. Goldhaber and J. N. Weiss, "Oxygen free radicals and cardiac reperfusion abnormalities," Hypertension, vol. 20, no. 1, pp. 118-127, 1992.

[20] J. Levraut, H. Iwase, Z. H. Shao, T. L. Vanden Hoek, and P. T. Schumacker, "Cell death during ischemia: relationship to mitochondrial depolarization and ROS generation," American Journal of Physiology-Heart and Circulatory Physiology, vol. 284, no. 2, pp. H549-H558, 2003.

[21] R. Ferrari, C. Ceconi, S. Curello et al., "Oxygen-mediated myocardial damage during ischameia and reperfusion: Role of the cellular defences against oxygen toxicity," Journal of Molecular and Cellular Cardiology, vol. 17, no. 10, pp. 937945, 1985.

[22] R. Rodrigo, "Prevention of postoperative atrial fibrillation: novel and safe strategy based on the modulation of the antioxidant system," Frontiers in Physiology, vol. 3, p. 93, 2012.

[23] S. Bae, M. Park, C. Kang et al., "Hydrogen peroxideresponsive nanoparticle reduces myocardial ischemia/reperfusion injury," Journal of the American Heart Association, vol. 5, no. 11, 2016.

[24] F. Tullio, C. Angotti, M. G. Perrelli, C. Penna, and P. Pagliaro, "Redox balance and cardioprotection," Basic Research in Cardiology, vol. 108, no. 6, p. 392, 2013.

[25] D. Chambers, D. Parks, G. Patterson et al., "Xanthine oxidase as a source of free radical damage in myocardial ischemia," Journal of Molecular and Cellular Cardiology, vol. 17, no. 2, pp. 145-152, 1985.

[26] Y. Ikeda, L. H. Young, R. Scalia, C. R. Ross, and A. M. Lefer, "PR-39, a proline/arginine-rich antimicrobial peptide, exerts cardioprotective effects in myocardial ischemia-reperfusion," Cardiovascular Research, vol. 49, no. 1, pp. 69-77, 2001.

[27] R. P. Brandes, N. Weissmann, and K. Schröder, "NADPH oxidases in cardiovascular disease," Free Radical Biology and Medicine, vol. 49, no. 5, pp. 687-706, 2010.

[28] G. Paradies, G. Petrosillo, M. Pistolese, N. Di Venosa, A. Federici, and F. M. Ruggiero, "Decrease in mitochondrial complex I activity in ischemic/reperfused rat heart: involvement of reactive oxygen species and cardiolipin," Circulation Research, vol. 94, no. 1, pp. 53-59, 2004.

[29] K. A. Perkins, S. Pershad, Q. Chen et al., "The effects of modulating eNOS activity and coupling in ischemia/reperfusion (I/R)," Naunyn-Schmiedeberg's Archives of Pharmacology, vol. 385, no. 1, pp. 27-38, 2012.

[30] D. N. Granger and P. R. Kvietys, "Reperfusion injury and reactive oxygen species: the evolution of a concept," Redox Biology, vol. 6, pp. 524-551, 2015.

[31] H. Cai, "Hydrogen peroxide regulation of endothelial function: origins, mechanisms, and consequences," Cardiovascular Research, vol. 68, no. 1, pp. 26-36, 2005.

[32] D. J. Granville, B. Tashakkor, C. Takeuchi et al., "Reduction of ischemia and reperfusion-induced myocardial damage by cytochrome P450 inhibitors," Proceedings of the National Academy of Sciences, vol. 101, no. 5, pp. 13211326, 2004.

[33] P. Bianchi, O. Kunduzova, E. Masini et al., "Oxidative stress by monoamine oxidase mediates receptor-independent cardiomyocyte apoptosis by serotonin and postischemic myo- cardial injury," Circulation, vol. 112, no. 21, pp. 3297-3305, 2005.

[34] Z. Q. Zhao, "Oxidative stress-elicited myocardial apoptosis during reperfusion," Current Opinion in Pharmacology, vol. 4, no. 2, pp. 159-165, 2004.

[35] L. G. Kevin, E. Novalija, and D. F. Stowe, "Reactive oxygen species as mediators of cardiac injury and protection: the relevance to anesthesia practice," Anesthesia \& Analgesia, vol. 101, no. 5, pp. 1275-1287, 2005.

[36] Y. R. Chen and J. L. Zweier, "Cardiac mitochondria and reactive oxygen species generation," Circulation Research, vol. 114, no. 3, pp. 524-537, 2014.

[37] M. D. Brand, "The sites and topology of mitochondrial superoxide production," Experimental Gerontology, vol. 45, no. 78, pp. 466-472, 2010.

[38] E. T. Chouchani, V. R. Pell, E. Gaude et al., "Ischaemic accumulation of succinate controls reperfusion injury through mitochondrial ROS," Nature, vol. 515, no. 7527, pp. 431435, 2014.

[39] E. T. Chouchani, V. R. Pell, A. M. James et al., "A Unifying Mechanism for Mitochondrial Superoxide Production during Ischemia- Reperfusion Injury," Cell Metabolism, vol. 23, no. 2, pp. 254-263, 2016.

[40] R. Bretón-Romero and S. Lamas, "Hydrogen peroxide signaling in vascular endothelial cells," Redox Biology, vol. 2, pp. 529-534, 2014.

[41] J. M. McCord, "Oxygen-derived free radicals in postischemic tissue injury," New England Journal of Medicine, vol. 312, no. 3, pp. 159-163, 1985.

[42] K. A. Reimer and R. B. Jennings, "Failure of the xanthine oxidase inhibitor allopurinol to limit infarct size after ischemia and reperfusion in dogs," Circulation, vol. 71, no. 5, pp. 1069-1075, 1985.

[43] J. Downey, T. Miura, L. Eddy et al., "Xanthine oxidase is not a source of free radicals in the ischemic rabbit heart," Journal of Molecular and Cellular Cardiology, vol. 19, no. 11, pp. 10531060, 1987.

[44] L. J. Eddy, J. R. Stewart, H. P. Jones, T. D. Engerson, J. M. McCord, and J. M. Downey, "Free radical-producing enzyme, xanthine oxidase, is undetectable in human hearts," American Journal of Physiology-Heart and Circulatory Physiology, vol. 253, 3 Part 2, pp. H709-H711, 1987.

[45] V. G. Nielsen, S. Tan, M. S. Baird, P. N. Samuelson, A. T. McCammon, and D. A. Parks, "Xanthine oxidase mediates myocardial injury after hepatoenteric ischemia-reperfusion," Critical Care Medicine, vol. 25, no. 6, pp. 1044-1050, 1997.

[46] M. C. Lee, M. Velayutham, T. Komatsu, R. Hille, and J. L. Zweier, "Measurement and characterization of superoxide generation from xanthine dehydrogenase: a redox-regulated pathway of radical generation in ischemic tissues," Biochemistry, vol. 53, no. 41, pp. 6615-6623, 2014.

[47] S. Jeddi, S. Gheibi, K. Kashfi, M. Carlström, and A. Ghasemi, "Dose-dependent effects of long-term administration of hydrogen sulfide on myocardial ischemia-reperfusion injury in male wistar rats: modulation of RKIP, NF- $\kappa$ B, and oxidative stress," International Journal of Molecular Sciences, vol. 21, no. 4, p. 1415, 2020.

[48] M. S. Alkaitis and M. J. Crabtree, "Recoupling the cardiac nitric oxide synthases: tetrahydrobiopterin synthesis and recycling," Current Heart Failure Reports, vol. 9, no. 3, pp. 200-210, 2012. 
[49] B. C. Smith, E. S. Underbakke, D. W. Kulp, W. R. Schief, and M. A. Marletta, "Nitric oxide synthase domain interfaces regulate electron transfer and calmodulin activation," Proceedings of the National Academy of Sciences, vol. 110, no. 38, pp. E3577-E3586, 2013.

[50] M. E. Armitage, K. Wingler, H. H. Schmidt, and M. la, "Translating the oxidative stress hypothesis into the clinic: NOX versus NOS," Journal of Molecular Medicine, vol. 87, no. 11, pp. 1071-1076, 2009.

[51] J. Vásquez-Vivar, B. Kalyanaraman, P. Martásek et al., "Superoxide generation by endothelial nitric oxide synthase: the influence of cofactors," Proceedings of the National Academy of Sciences, vol. 95, no. 16, pp. 9220-9225, 1998.

[52] H. Cai, Z. Li, S. Dikalov et al., "NAD(P)H Oxidase-derived Hydrogen Peroxide Mediates Endothelial Nitric Oxide Production in Response to Angiotensin II," Journal of Biological Chemistry, vol. 277, no. 50, pp. 48311-48317, 2002.

[53] H. Cai, M. E. Davis, G. R. Drummond, and D. G. Harrison, "Induction of endothelial NO synthase by hydrogen peroxide via a Ca2+/Calmodulin-Dependent protein kinase II/janus kinase 2-dependent pathway," Arteriosclerosis, Thrombosis, and Vascular Biology, vol. 21, no. 10, pp. 1571-1576, 2001.

[54] M. Neri, I. Riezzo, N. Pascale, C. Pomara, and E. Turillazzi, "Ischemia/reperfusion injury following acute myocardial infarction: a critical issue for clinicians and forensic pathologists," Mediators of Inflammation, vol. 2017, Article ID 7018393, 14 pages, 2017.

[55] B. I. Jugdutt, "Nitric oxide and cardioprotection during ischemia-reperfusion," Heart Failure Reviews, vol. 7, no. 4, pp. 391-405, 2002.

[56] C. Szabó, H. Ischiropoulos, and R. Radi, "Peroxynitrite: biochemistry, pathophysiology and development of therapeutics," Nature Reviews Drug Discovery, vol. 6, no. 8, pp. 662-680, 2007.

[57] W. Yasmin, K. D. Strynadka, and R. Schulz, "Generation of peroxynitrite contributes to ischemia-reperfusion injury in isolated rat hearts," Cardiovascular Research, vol. 33, no. 2, pp. 422-432, 1997.

[58] T. Kahles and R. P. Brandes, "Which NADPH oxidase isoform is relevant for ischemic stroke? The case for nox 2," Antioxidants \& Redox Signaling, vol. 18, no. 12, pp. 14001417, 2013.

[59] K. Bedard and K. H. Krause, "The NOX family of ROSgenerating NADPH oxidases: physiology and pathophysiology," Physiological Reviews, vol. 87, no. 1, pp. 245-313, 2007.

[60] I. Takac, K. Schröder, L. Zhang et al., "The E-loop Is Involved in Hydrogen Peroxide Formation by the NADPH Oxidase Nox4," Journal of Biological Chemistry, vol. 286, no. 15, pp. 13304-13313, 2011.

[61] K. D. Martyn, L. M. Frederick, K. von Loehneysen, M. C. Dinauer, and U. G. Knaus, "Functional analysis of Nox4 reveals unique characteristics compared to other NADPH oxidases," Cellular Signalling, vol. 18, no. 1, pp. 69-82, 2006.

[62] S. Altenhöfer, P. W. Kleikers, K. A. Radermacher et al., "The NOX toolbox: validating the role of NADPH oxidases in physiology and disease," Cellular and Molecular Life Sciences, vol. 69, no. 14, pp. 2327-2343, 2012.

[63] N. E. Hahn, C. Meischl, T. Kawahara et al., "NOX5 expression is increased in intramyocardial blood vessels and cardiomyocytes after acute myocardial infarction in humans," The
American Journal of Pathology, vol. 180, no. 6, pp. 22222229, 2012.

[64] S. Matsushima, J. Kuroda, T. Ago et al., "Broad suppression of NADPH oxidase activity exacerbates ischemia/reperfusion injury through inadvertent downregulation of hypoxiainducible factor- $1 \alpha$ and upregulation of peroxisome proliferator-activated receptor- $\alpha$," Circulation Research, vol. 112, no. 8, pp. 1135-1149, 2013.

[65] R. Rodrigo, M. Cereceda, R. Castillo et al., "Prevention of atrial fibrillation following cardiac surgery: basis for a novel therapeutic strategy based on non-hypoxic myocardial preconditioning," Pharmacology \& Therapeutics, vol. 118, no. 1, pp. 104-127, 2008.

[66] J. M. Li and A. M. Shah, "Endothelial cell superoxide generation: regulation and relevance for cardiovascular pathophysiology," American Journal of Physiology-Regulatory, Integrative and Comparative Physiology, vol. 287, no. 5, pp. R1014-R1030, 2004.

[67] S. Zhang, Y. Lin, Y. S. Kim, M. P. Hande, Z. G. Liu, and H. M. Shen, "c-Jun N-terminal kinase mediates hydrogen peroxideinduced cell death via sustained poly(ADP-ribose) polymerase-1 activation," Cell Death and Differentiation, vol. 14, no. 5, pp. 1001-1010, 2007.

[68] T. L. vanden Hoek, Y. Qin, K. Wojcik et al., "Reperfusion, not simulated ischemia, initiates intrinsic apoptosis injury in chick cardiomyocytes," American Journal of Physiology-Heart and Circulatory Physiology, vol. 284, no. 1, pp. H141H150, 2003.

[69] C. Li and R. M. Jackson, "Reactive species mechanisms of cellular hypoxia-reoxygenation injury," American Journal of Physiology-Cell Physiology, vol. 282, no. 2, pp. C227-C241, 2002.

[70] X. Wu, C. Molinaro, N. Johnson, and C. A. Casiano, "Secondary necrosis is a source of proteolytically modified forms of specific intracellular autoantigens: implications for systemic autoimmunity," Arthritis \& Rheumatology, vol. 44, no. 11, pp. 2642-2652, 2001.

[71] A. Samali, H. Nordgren, B. Zhivotovsky, E. Peterson, and S. Orrenius, "A comparative study of apoptosis and necrosis in HepG2 cells: oxidant-induced caspase inactivation leads to necrosis," Biochemical and Biophysical Research Communications, vol. 255, no. 1, pp. 6-11, 1999.

[72] M. Leist, B. Single, H. Naumann et al., "Inhibition of mitochondrial ATP generation by nitric oxide switches apoptosis to necrosis," Experimental Cell Research, vol. 249, no. 2, pp. 396-403, 1999.

[73] J. P. Schmitt, J. Schröder, H. Schunkert, D. E. Birnbaum, and H. Aebert, "Role of apoptosis in myocardial stunning after open heart surgery," The Annals of Thoracic Surgery, vol. 73, no. 4, pp. 1229-1235, 2002.

[74] Z. Q. Zhao, C. D. Morris, J. M. Budde et al., "Inhibition of myocardial apoptosis reduces infarct size and improves regional contractile dysfunction during reperfusion," Cardiovascular Research, vol. 59, no. 1, pp. 132-142, 2003.

[75] F. Qin, J. Shite, and C. S. Liang, "Antioxidants attenuate myocyte apoptosis and improve cardiac function in CHF: association with changes in MAPK pathways," American Journal of Physiology-Heart and Circulatory Physiology, vol. 285, no. 2, pp. H822-H832, 2003.

[76] P. A. MacCarthy and A. M. Shah, "Oxidative stress and heart failure," Coronary Artery Disease, vol. 14, no. 2, pp. 109-113, 2003. 
[77] J. Chandra, A. Samali, and S. Orrenius, "Triggering and modulation of apoptosis by oxidative stress," Free Radical Biology and Medicine, vol. 29, no. 3-4, pp. 323-333, 2000.

[78] T. Kalogeris, Y. Bao, and R. J. Korthuis, "Mitochondrial reactive oxygen species: a double edged sword in ischemia/reperfusion vs preconditioning," Redox Biology, vol. 2, pp. 702-714, 2014.

[79] L. Li, Y. Zhou, Y. Li et al., "Aqueous extract of Cortex Dictamni protects $\mathrm{H} 9 \mathrm{c} 2$ cardiomyocytes from hypoxia/reoxygenation-induced oxidative stress and apoptosis by PI3K/Akt signaling pathway," Biomedicine \& Pharmacotherapy, vol. 89, pp. 233-244, 2017.

[80] A. Haunstetter and S. Izumo, "Apoptosis: basic mechanisms and implications for cardiovascular disease," Circulation Research, vol. 82, no. 11, pp. 1111-1129, 1998.

[81] C. Brooks and Z. Dong, "Regulation of mitochondrial morphological dynamics during apoptosis by Bcl-2 family proteins: a key in Bak?," Cell Cycle, vol. 6, no. 24, pp. 3043-3047, 2007.

[82] X. Li, P. Jia, Z. Huang et al., "Lycopene protects against myocardial ischemia-reperfusion injury by inhibiting mitochondrial permeability transition pore opening," Drug Design, Development and Therapy, vol. Volume 13, pp. 2331-2342, 2019.

[83] R. von Harsdorf, P. F. Li, and R. Dietz, "Signaling pathways in reactive oxygen species-induced cardiomyocyte apoptosis," Circulation, vol. 99, no. 22, pp. 2934-2941, 1999.

[84] R. Schreck, P. Rieber, and P. A. Baeuerle, "Reactive oxygen intermediates as apparently widely used messengers in the activation of the NF-kappa B transcription factor and HIV1," The EMBO Journal, vol. 10, no. 8, pp. 2247-2258, 1991.

[85] V. Imbert, R. A. Rupec, A. Livolsi et al., "Tyrosine Phosphorylation of I $\kappa \mathrm{B}-\alpha$ Activates NF- $\kappa \mathrm{B}$ without Proteolytic Degradation of I $\kappa$ B- $\alpha$," Cell, vol. 86, no. 5, pp. 787-798, 1996.

[86] A. Bowie and L. A. O'Neill, "Oxidative stress and nuclear factor- $\kappa \mathrm{B}$ activation: A reassessment of the evidence in the light of recent discoveries," Biochemical Pharmacology, vol. 59, no. 1, pp. 13-23, 2000.

[87] J. Zeng, Q. Jin, Y. Ruan et al., "Inhibition of TGF $\beta$-activated protein kinase 1 ameliorates myocardial ischaemia/reperfusion injury via endoplasmic reticulum stress suppression," Journal of Cellular and Molecular Medicine, vol. 24, no. 12, pp. 6846-6859, 2020.

[88] J. I. E. Mariángelo, B. Román, M. A. Silvestri et al., "Chemical chaperones improve the functional recovery of stunned myocardium by attenuating the endoplasmic reticulum stress," Acta Physiologica, vol. 228, no. 2, article e13358, 2020.

[89] L. Jian, Y. Lu, S. Lu, and C. Lu, "Chemical chaperone 4phenylbutyric acid reduces cardiac ischemia/reperfusion injury by alleviating endoplasmic reticulum stress and oxidative stress," Medical Science Monitor, vol. 22, pp. 5218-5227, 2016.

[90] Y. H. Chen, H. Lin, Q. Wang, J. W. Hou, Z. J. Mao, and Y. G. Li, "Protective role of silibinin against myocardial ischemia/reperfusion injury-induced cardiac dysfunction," International Journal of Biological Sciences, vol. 16, no. 11, pp. 1972-1988, 2020.

[91] M. Kaneko, R. E. Beamish, and N. S. Dhalla, "Depression of heart sarcolemmal Ca2+-pump activity by oxygen free radicals," American Journal of Physiology-Heart and Circulatory Physiology, vol. 256, 2 Part 2, pp. H368-H374, 1989.
[92] T. Chakraborti, T. Chakraborti, J. R. Michael, S. K. Batabyal, and S. K. Ghosh, "Targets of oxidative stress in cardiovascular system," Molecular and Cellular Biochemistry, vol. 187, no. 1/2, pp. 1-10, 1998.

[93] M. S. Kim and T. Akera, " $\mathrm{O}_{2}$ free radicals: cause of ischemiareperfusion injury to cardiac Na+-K+-ATPase," American Journal of Physiology-Heart and Circulatory Physiology, vol. 252, no. 2, pp. H252-H257, 1987.

[94] J. I. Goldhaber, "Free radicals enhance $\mathrm{Na}+/ \mathrm{Ca}_{2}+$ exchange in ventricular myocytes," American Journal of Physiology-Heart and Circulatory Physiology, vol. 271, no. 3, pp. H823H833, 1996.

[95] M. Hori and K. Nishida, "Oxidative stress and left ventricular remodelling after myocardial infarction," Cardiovascular Research, vol. 81, no. 3, pp. 457-464, 2008.

[96] D. J. Hausenloy, E. A. Boston-Griffiths, and D. M. Yellon, "Cyclosporin A and cardioprotection: from investigative tool to therapeutic agent," British Journal of Pharmacology, vol. 165, no. 5, pp. 1235-1245, 2012.

[97] Y. Zhao, Y. Guo, Y. Chen, S. Liu, N. Wu, and D. Jia, "Curculigoside attenuates myocardial ischemia-reperfusion injury by inhibiting the opening of the mitochondrial permeability transition pore," International Journal of Molecular Medicine, vol. 45, no. 5, pp. 1514-1524, 2020.

[98] C. K. Lam, W. Zhao, G. S. Liu et al., "HAX-1 regulates cyclophilin-D levels and mitochondria permeability transition pore in the heart," Proceedings of the National Academy of Sciences, vol. 112, no. 47, pp. E6466-E6475, 2015.

[99] X. Yang, M. V. Cohen, and J. M. Downey, "Mechanism of cardioprotection by early ischemic preconditioning," Cardiovascular Drugs and Therapy, vol. 24, no. 3, pp. 225-234, 2010.

[100] A. P. Halestrap, "A pore way to die: the role of mitochondria in reperfusion injury and cardioprotection," Biochemical Society Transactions, vol. 38, no. 4, pp. 841-860, 2010.

[101] E. Murphy and C. Steenbergen, "Mechanisms underlying acute protection from cardiac ischemia-reperfusion injury," Biochemical Society Transactions, vol. 88, no. 2, pp. 581609, 2008.

[102] S. Javadov, M. Karmazyn, and N. Escobales, "Mitochondrial permeability transition pore opening as a promising therapeutic target in cardiac diseases," Journal of Pharmacology and Experimental Therapeutics, vol. 330, no. 3, pp. 670-678, 2009.

[103] C. P. Connern and A. P. Halestrap, "Recruitment of mitochondrial cyclophilin to the mitochondrial inner membrane under conditions of oxidative stress that enhance the opening of a calcium-sensitive non-specific channel," Biochemical Journal, vol. 302, no. 2, pp. 321-324, 1994.

[104] W. M. Bennett and D. J. Norman, "Action and toxicity of cyclosporine," Annual Review of Medicine, vol. 37, pp. 215224, 1986.

[105] J. W. Elrod, R. Wong, S. Mishra et al., "Cyclophilin D controls mitochondrial pore-dependent $\mathrm{Ca}(2+)$ exchange, metabolic flexibility, and propensity for heart failure in mice," Journal of Clinical Investigation, vol. 120, no. 10, pp. 3680-3687, 2010.

[106] N. Fournier, G. Ducet, and A. Crevat, "Action of cyclosporine on mitochondrial calcium fluxes," Journal of Bioenergetics and Biomembranes, vol. 19, no. 3, pp. 297-303, 1987. 
[107] S. B. Ong, R. K. Dongworth, H. A. Cabrera-Fuentes, and D. J. Hausenloy, "Role of the MPTP in conditioning the heart translatability and mechanism," British Journal of Pharmacology, vol. 172, no. 8, pp. 2074-2084, 2015.

[108] Z. Yu, S. Wang, X. Zhang, Y. Li, Q. Zhao, and T. Liu, "Pterostilbene protects against myocardial ischemia/reperfusion injury via suppressing oxidative/nitrative stress and inflammatory response," International Immunopharmacology, vol. 43, pp. 7-15, 2017.

[109] K. Tobiume, A. Matsuzawa, T. Takahashi et al., "ASK1 is required for sustained activations of JNK/p38 MAP kinases and apoptosis," EMBO Reports, vol. 2, no. 3, pp. 222-228, 2001.

[110] K. Lei, A. Nimnual, W. X. Zong et al., "The Bax subfamily of $\mathrm{Bcl} 2$-related proteins is essential for apoptotic signal transduction by c-Jun $\mathrm{NH}(2)$-terminal kinase," Molecular and Cellular Biology, vol. 22, no. 13, pp. 4929-4942, 2002.

[111] S. Cicconi, N. Ventura, D. Pastore et al., "Characterization of apoptosis signal transduction pathways in HL-5 cardiomyocytes exposed to ischemia/reperfusion oxidative stress model," Journal of Cellular Physiology, vol. 195, no. 1, pp. 27-37, 2003.

[112] T. Force, C. M. Pombo, J. A. Avruch, J. V. Bonventre, and J. M. Kyriakis, "Stress-activated protein kinases in cardiovascular disease," Circulation Research, vol. 78, no. 6, pp. 947953, 1996.

[113] R. Aikawa, I. Komuro, T. Yamazaki et al., "Oxidative stress activates extracellular signal-regulated kinases through Src and Ras in cultured cardiac myocytes of neonatal rats," Journal of Clinical Investigation, vol. 100, no. 7, pp. 1813-1821, 1997.

[114] W. Guo, X. Liu, J. Li et al., "Prdx1 alleviates cardiomyocyte apoptosis through ROS-activated MAPK pathway during myocardial ischemia/reperfusion injury," International Journal of Biological Macromolecules, vol. 112, pp. 608-615, 2018.

[115] A. S. Clanachan, J. S. Jaswal, M. Gandhi et al., "Effects of inhibition of myocardial extracellular-responsive kinase and P38 mitogen-activated protein kinase on mechanical function of rat hearts after prolonged hypothermic ischemia," Transplantation, vol. 75, no. 2, pp. 173-180, 2003.

[116] F. Gao, T. L. Yue, D. W. Shi, T. A. Christopher, B. L. Lopez, and E. H. Ohlstein, "p38 MAPK inhibition reduces myocardial reperfusion injury via inhibition of endothelial adhesion molecule expression and blockade of PMN accumulation," Cardiovascular Research, vol. 53, no. 2, pp. 414-422, 2002.

[117] X. L. Ma, S. Kumar, F. Gao et al., "Inhibition of p38 mitogenactivated protein kinase decreases cardiomyocyte apoptosis and improves cardiac function after myocardial ischemia and reperfusion," Circulation, vol. 99, no. 13, pp. 16851691, 1999.

[118] M. Damarla, A. R. Parniani, L. Johnston et al., "Mitogen-activated protein kinase-activated protein kinase 2 mediates apoptosis during lung vascular permeability by regulating movement of cleaved caspase 3," American Journal of Respiratory Cell and Molecular Biology, vol. 50, no. 5, pp. 932941, 2014.

[119] K. Shiroto, H. Otani, F. Yamamoto, C. Huang, N. Maulik, and D. Das, "MK2 $2^{-1-}$ gene knockout mouse hearts carry antiapoptotic signal and are resistant to ischemia reperfusion injury," Journal of Molecular and Cellular Cardiology, vol. 38, no. 1, pp. 93-97, 2005.
[120] A. Barajas-Espinosa, A. Basye, M. G. Angelos, and C. A. Chen, "Modulation of p38 kinase by DUSP4 is important in regulating cardiovascular function under oxidative stress," Free Radical Biology and Medicine, vol. 89, pp. 170-181, 2015.

[121] F. Wang, H. Wang, X. Liu et al., "Neuregulin-1 alleviate oxidative stress and mitigate inflammation by suppressing NOX4 and NLRP3/caspase-1 in myocardial ischaemiareperfusion injury," Journal of Cellular and Molecular Medicine, vol. 25, no. 3, pp. 1783-1795, 2021.

[122] Z. Xia, M. Dickens, J. Raingeaud, R. J. Davis, and M. E. Greenberg, "Opposing effects of ERK and JNK-p38 MAP kinases on apoptosis," Science, vol. 270, no. 5240, pp. 13261331, 1995.

[123] Y. Ruan, J. Zeng, Q. Jin et al., "Endoplasmic reticulum stress serves an important role in cardiac ischemia/reperfusion injury (Review)," Experimental and Therapeutic Medicine, vol. 20, no. 6, p. 268, 2020.

[124] X. L. Yin, W. Zhang, Y. Yang, and H. Shen, "Increasing expression of (CCAAT enhancer binding protein) homologous protein induced by endoplasmic reticulum stress in myocardium after cardiac arrest and resuscitation in rat," Resuscitation, vol. 83, no. 3, pp. 378-385, 2012.

[125] T. Minamino and M. Kitakaze, "ER stress in cardiovascular disease," Journal of Molecular and Cellular Cardiology, vol. 48, no. 6, pp. 1105-1110, 2010.

[126] C. Xu, B. Bailly-Maitre, and J. C. Reed, "Endoplasmic reticulum stress: cell life and death decisions," Journal of Clinical Investigation, vol. 115, no. 10, pp. 2656-2664, 2005.

[127] D. Han, Y. Wang, J. Chen et al., "Activation of melatonin receptor 2 but not melatonin receptor 1 mediates melatonin-conferred cardioprotection against myocardial ischemia/reperfusion injury," Journal of Pineal Research, vol. 67, no. 1, article e12571, 2019.

[128] P. Codogno and A. J. Meijer, "Autophagy and signaling: their role in cell survival and cell death," Cell Death and Differentiation, vol. 12, Suppl 2, pp. 1509-1518, 2005.

[129] E. Iwai-Kanai, H. Yuan, C. Huang et al., "A method to measure cardiac autophagic flux in vivo," Autophagy, vol. 4, no. 3, pp. 322-329, 2008.

[130] N. R. Brady, A. Hamacher-Brady, H. Yuan, and R. A. Gottlieb, "The autophagic response to nutrient deprivation in the hl-1 cardiac myocyte is modulated by Bcl-2 and sarco/endoplasmic reticulum calcium stores," FEBS Journal, vol. 274, no. 12, pp. 3184-3197, 2007.

[131] S. Sciarretta, P. Zhai, D. Shao et al., "Rheb is a critical regulator of autophagy during myocardial ischemia: pathophysiological implications in obesity and metabolic syndrome," Circulation, vol. 125, no. 9, pp. 1134-1146, 2012.

[132] Y. Matsui, H. Takagi, X. Qu et al., "Distinct roles of autophagy in the heart during ischemia and reperfusion: roles of AMP-activated protein kinase and Beclin 1 in mediating autophagy," Circulation Research, vol. 100, no. 6, pp. 914922, 2007.

[133] S. Sciarretta, Y. Maejima, D. Zablocki, and J. Sadoshima, "The role of autophagy in the heart," Annual Review of Physiology, vol. 80, no. 1, pp. 1-26, 2018.

[134] P. Zhai, S. Sciarretta, J. Galeotti, M. Volpe, and J. Sadoshima, "Differential roles of GSK-3 $\beta$ during myocardial ischemia and ischemia/reperfusion," Circulation Research, vol. 109, no. 5, pp. 502-511, 2011. 
[135] T. Aoyagi, Y. Kusakari, C. Y. Xiao et al., "Cardiac mTOR protects the heart against ischemia-reperfusion injury," American Journal of Physiology-Heart and Circulatory Physiology, vol. 303, no. 1, pp. H75-H85, 2012.

[136] S. Wu, G. Chang, L. Gao et al., "Trimetazidine protects against myocardial ischemia/reperfusion injury by inhibiting excessive autophagy," Journal of Molecular Medicine, vol. 96, no. 8, pp. 791-806, 2018.

[137] N. Hariharan, P. Zhai, and J. Sadoshima, "Oxidative stress stimulates autophagic flux during ischemia/reperfusion," Antioxidants \& Redox Signaling, vol. 14, no. 11, pp. 21792190, 2011.

[138] M. Høyer-Hansen, L. Bastholm, P. Szyniarowski et al., "Control of Macroautophagy by Calcium, Calmodulin-Dependent Kinase Kinase- $\beta$, and Bcl-2," Molecular Cell, vol. 25, no. 2, pp. 193-205, 2007.

[139] D. D. Arrington, T. R. Van Vleet, and R. G. Schnellmann, "Calpain 10: a mitochondrial calpain and its role in calcium-induced mitochondrial dysfunction," American Journal of Physiology-Cell Physiology, vol. 291, no. 6, pp. C1159-C1171, 2006.

[140] R. S. Carreira, Y. Lee, M. Ghochani, Å. B. Gustafsson, and R. A. Gottlieb, "Cyclophilin D is required for mitochondrial removal by autophagy in cardiac cells," Autophagy, vol. 6, no. 4, pp. 462-472, 2010.

[141] D. Gozuacik and A. Kimchi, "Autophagy and cell death," Current Topics in Developmental Biology, vol. 78, pp. 217245, 2007.

[142] M. C. Maiuri, G. le Toumelin, A. Criollo et al., "Functional and physical interaction between $\mathrm{Bcl}-\mathrm{X}(\mathrm{L})$ and a $\mathrm{BH}$-like domain in Beclin-1," The EMBO Journal, vol. 26, no. 10, pp. 2527-2539, 2007.

[143] A. Hamacher-Brady, N. R. Brady, and R. A. Gottlieb, “The interplay between pro-death and pro-survival signaling pathways in myocardial ischemia/reperfusion injury: apoptosis meets autophagy," Cardiovascular Drugs and Therapy, vol. 20, no. 6, pp. 445-462, 2006.

[144] H. Ma, R. Guo, L. Yu, Y. Zhang, and J. Ren, “Aldehyde dehydrogenase 2 (ALDH2) rescues myocardial ischaemia/reperfusion injury: role of autophagy paradox and toxic aldehyde," European Heart Journal, vol. 32, no. 8, pp. 1025-1038, 2011.

[145] L. Yan, J. Sadoshima, D. E. Vatner, and S. F. Vatner, "Autophagy in ischemic preconditioning and hibernating myocardium," Autophagy, vol. 5, no. 5, pp. 709-712, 2009.

[146] A. Hamacher-Brady, N. R. Brady, and R. A. Gottlieb, "Enhancing macroautophagy protects against ischemia/reperfusion injury in cardiac myocytes," The Journal of Biological Chemistry, vol. 281, no. 40, pp. 29776-29787, 2006.

[147] A. Hamacher-Brady, N. R. Brady, R. A. Gottlieb, and A. B. Gustafsson, "Autophagy as a protective response to Bnip3mediated apoptotic signaling in the heart," Autophagy, vol. 2, no. 4, pp. 307-309, 2006.

[148] L. Yan, D. E. Vatner, S. J. Kim, H. Ge, M. Masurekar, and W. H. Massover, "Autophagy in chronically ischemic myocardium," Proceedings of the National Academy of Sciences of the United States of America, vol. 102, no. 39, pp. 1380713812, 2005.

[149] A. B. Gustafsson and R. A. Gottlieb, "Autophagy in ischemic heart disease," Circulation Research, vol. 104, no. 2, pp. 150158, 2009.
[150] R. S. Decker and K. Wildenthal, "Lysosomal alterations in hypoxic and reoxygenated hearts. I. Ultrastructural and cytochemical changes," The American Journal of Pathology, vol. 98, no. 2, pp. 425-444, 1980.

[151] X. Ma, H. Liu, S. R. Foyil, R. J. Godar, C. J. Weinheimer, and J. A. Hill, "Impaired autophagosome clearance contributes to cardiomyocyte death in ischemia/reperfusion injury," Circulation, vol. 125, no. 25, pp. 3170-3181, 2012.

[152] U. T. Brunk and A. Terman, "The mitochondrial-lysosomal axis theory of aging: accumulation of damaged mitochondria as a result of imperfect autophagocytosis," European Journal of Biochemistry, vol. 269, no. 8, pp. 1996-2002, 2002.

[153] P. Saftig, Y. Tanaka, R. Lüllmann-Rauch, and K. von Figura, "Disease model: LAMP-2 enlightens Danon disease," Trends in Molecular Medicine, vol. 7, no. 1, pp. 37-39, 2001.

[154] X. Ma, H. Liu, S. R. Foyil, R. J. Godar, C. J. Weinheimer, and A. Diwan, "Autophagy is impaired in cardiac ischemiareperfusion injury," Autophagy, vol. 8, no. 9, pp. 1394-1396, 2012.

[155] H. Xie, Q. Xu, J. Jia, G. Ao, Y. Sun, and L. Hu, "Hydrogen sulfide protects against myocardial ischemia and reperfusion injury by activating AMP-activated protein kinase to restore autophagic flux," Biochemical and Biophysical Research Communications, vol. 458, no. 3, pp. 632-638, 2015.

[156] S. Sciarretta, N. Hariharan, Y. Monden, D. Zablocki, and J. Sadoshima, "Is autophagy in response to ischemia and reperfusion protective or detrimental for the heart?," Pediatric Cardiology, vol. 32, no. 3, pp. 275-281, 2011.

[157] L. Yu, F. Wan, S. Dutta, S. Welsh, Z. Liu, and E. Freundt, "Autophagic programmed cell death by selective catalase degradation," Proceedings of the National Academy of Sciences of the United States of America, vol. 103, no. 13, pp. 4952-4957, 2006.

[158] R. Gill, A. Tsung, and T. Billiar, "Linking oxidative stress to inflammation: Toll-like receptors," Free Radical Biology \& Medicine, vol. 48, no. 9, pp. 1121-1132, 2010.

[159] R. Huang, J. Shu, X. Dai, Y. Liu, F. Yu, and G. Shi, “The protective effect of polyphyllin I on myocardial ischemia/reperfusion injury in rats," Annals of translational medicine, vol. 8, no. 10, p. 644, 2020.

[160] Y. Liu, K. Lian, L. Zhang, R. Wang, F. Yi, and C. Gao, “TXNIP mediates NLRP3 inflammasome activation in cardiac microvascular endothelial cells as a novel mechanism in myocardial ischemia/reperfusion injury," Basic Research in Cardiology, vol. 109, no. 5, p. 415, 2014.

[161] W. Yang, Q. Lai, L. Zhang, Y. Zhang, Y. Zhang, and B. Yu, "Mechanisms dissection of the combination GRS derived from ShengMai preparations for the treatment of myocardial ischemia/reperfusion injury," Journal of Ethnopharmacology, vol. 264, p. 113381, 2021.

[162] R. Wang, M. Wang, J. Zhou, T. Ye, X. Xie, and D. Ni, "Shuxuening injection protects against myocardial ischemia-reperfusion injury through reducing oxidative stress, inflammation and thrombosis," Annals of translational medicine, vol. 7, no. 20, p. 562, 2019.

[163] C. Zhao, Y. Yang, Y. An, B. Yang, and P. Li, "Cardioprotective role of phyllanthin against myocardial ischemiareperfusion injury by alleviating oxidative stress and inflammation with increased adenosine triphosphate levels in the mice model," Environmental Toxicology, vol. 36, no. 1, pp. 33-44, 2020. 
[164] B. Yang, J. Wang, Y. Zhao, W. Duan, C. Dai, and Z. Han, "Attenuating ischemia/reperfusion injury in rat cardiac transplantation by intracoronary infusion with siRNA cocktail solution," Bioscience Reports, vol. 40, no. 8, 2020.

[165] D. J. Lefer and D. N. Granger, "Oxidative stress and cardiac disease," The American Journal of Medicine, vol. 109, no. 4, pp. 315-323, 2000.

[166] X. Guo, S. Hong, H. He, Y. Zeng, Y. Chen, and X. Mo, "NF $\kappa B$ promotes oxidative stress-induced necrosis and ischemia/reperfusion injury by inhibiting Nrf2-ARE pathway," Free Radical Biology \& Medicine, vol. 159, pp. 125-135, 2020.

[167] D. R. Janero, "Ischemic heart disease and antioxidants: mechanistic aspects of oxidative injury and its prevention," Critical Reviews in Food Science and Nutrition, vol. 35, no. 1-2, pp. 65-81, 1995.

[168] A. Devarajan, N. Bourquard, S. Hama, M. Navab, V. R. Grijalva, and S. Morvardi, "Paraoxonase 2 deficiency alters mitochondrial function and exacerbates the development of atherosclerosis," Antioxidants \& Redox Signaling, vol. 14, no. 3, pp. 341-351, 2011.

[169] D. Sulaiman, J. Li, A. Devarajan, C. M. Cunningham, M. Li, and G. A. Fishbein, "Paraoxonase 2 protects against acute myocardial ischemia-reperfusion injury by modulating mitochondrial function and oxidative stress via the PI3K/Akt/GSK-3 $\beta$ RISK pathway," Journal of Molecular and Cellular Cardiology, vol. 129, pp. 154-164, 2019.

[170] E. T. Chouchani, C. Methner, S. M. Nadtochiy, A. Logan, V. R. Pell, and S. Ding, "Cardioprotection by S-nitrosation of a cysteine switch on mitochondrial complex I," Nature Medicine, vol. 19, no. 6, pp. 753-759, 2013.

[171] Q. Zhao, Z. Liu, B. Huang, Y. Yuan, X. Liu, and H. Zhang, "PEDF improves cardiac function in rats subjected to myocardial ischemia/reperfusion injury by inhibiting ROS generation via PEDF-R," International Journal of Molecular Medicine, vol. 41, no. 6, pp. 3243-3252, 2018.

[172] S. Lahnwong, S. Palee, N. Apaijai, S. Sriwichaiin, S. Kerdphoo, and T. Jaiwongkam, "Acute dapagliflozin administration exerts cardioprotective effects in rats with cardiac ischemia/reperfusion injury," Cardiovascular Diabetology, vol. 19, no. 1, p. 91, 2020.

[173] M. Bredemeier, L. M. Lopes, M. A. Eisenreich, S. Hickmann, G. K. Bongiorno, and R. d'Avila, "Xanthine oxidase inhibitors for prevention of cardiovascular events: a systematic review and meta-analysis of randomized controlled trials," BMC cardiovascular disorders, vol. 18, no. 1, p. 24, 2018.

[174] J. R. Stewart, S. L. Crute, V. Loughlin, M. L. Hess, and L. J. Greenfield, "Prevention of free radical-induced myocardial reperfusion injury with allopurinol," The Journal of Thoracic and Cardiovascular Surgery, vol. 90, no. 1, pp. 68-72, 1985.

[175] D. V. Godin, S. Bhimji, and J. H. McNeill, "Effects of allopurinol pretreatment on myocardial ultrastructure and arrhythmias following coronary artery occlusion and reperfusion," Virchows Archiv B, vol. 52, no. 4, pp. 327-341, 1986.

[176] S. W. Werns, M. J. Shea, S. E. Mitsos, R. C. Dysko, J. C. Fantone, and M. A. Schork, "Reduction of the size of infarction by allopurinol in the ischemic-reperfused canine heart," Circulation, vol. 73, no. 3, pp. 518-524, 1986.

[177] W. Guan, T. Osanai, T. Kamada, H. Hanada, H. Ishizaka, and H. Onodera, "Effect of allopurinol pretreatment on free radical generation after primary coronary angioplasty for acute myocardial infarction," Journal of Cardiovascular Pharmacology, vol. 41, no. 5, pp. 699-705, 2003.
[178] P. Castelli, A. M. Condemi, C. Brambillasca, P. Fundarò, M. Botta, and M. Lemma, "Improvement of cardiac function by allopurinol in patients undergoing cardiac surgery," Journal of Cardiovascular Pharmacology, vol. 25, no. 1, pp. 119125, 1995.

[179] W. D. Johnson, K. L. Kayser, J. B. Brenowitz, and S. F. Saedi, "A randomized controlled trial of allopurinol in coronary bypass surgery," American Heart Journal, vol. 121, 1 Part 1, pp. 20-24, 1991.

[180] L. Xie, M. A. Talukder, J. Sun, S. Varadharaj, and J. L. Zweier, "Liposomal tetrahydrobiopterin preserves eNOS coupling in the post-ischemic heart conferring in vivo cardioprotection," Journal of Molecular and Cellular Cardiology, vol. 86, pp. 1422, 2015.

[181] L. L. Wan, J. Xia, D. Ye, J. Liu, J. Chen, and G. Wang, "Effects of quercetin on gene and protein expression of NOX and NOS after myocardial ischemia and reperfusion in rabbit," Cardiovascular Therapeutics, vol. 27, no. 1, pp. 28-33, 2009.

[182] X. Zhao, Y. R. Chen, G. He, A. Zhang, L. J. Druhan, and A. R. Strauch, "Endothelial nitric oxide synthase (NOS3) knockout decreases NOS2 induction, limiting hyperoxygenation and conferring protection in the postischemic heart," American Journal of Physiology. Heart and Circulatory Physiology, vol. 292, no. 3, pp. H1541-H1550, 2007.

[183] L. Ji, F. Fu, L. Zhang, W. Liu, X. Cai, and L. Zhang, "Insulin attenuates myocardial ischemia/reperfusion injury via reducing oxidative/nitrative stress," American Journal of Physiology. Endocrinology and Metabolism, vol. 298, no. 4, pp. E871-E880, 2010.

[184] Y. Fu, Z. Wang, W. L. Chen, P. K. Moore, and Y. Z. Zhu, "Cardioprotective effects of nitric oxide-aspirin in myocardial ischemia-reperfused rats," American Journal of Physiology. Heart and Circulatory Physiology, vol. 293, no. 3, pp. H1545-H1552, 2007.

[185] F. T. H. Yu, X. Chen, A. C. Straub, and J. J. Pacella, "The role of nitric oxide during sonoreperfusion of microvascular obstruction," Theranostics, vol. 7, no. 14, pp. 3527-3538, 2017.

[186] Q. Jin, Y. Jiang, L. Fu, Y. Zheng, Y. Ding, and Q. Liu, "Wenxin granule ameliorates hypoxia/reoxygenation-induced oxidative stress in mitochondria via the PKC- $\delta / \mathrm{NOX} 2 / \mathrm{ROS}$ pathway in H9c2 cells," Oxidative Medicine and Cellular Longevity, vol. 2020, Article ID 3245483, 16 pages, 2020.

[187] X. Y. Yang, N. Zhao, Y. Y. Liu, B. H. Hu, K. Sun, and X. Chang, "Inhibition of NADPH oxidase mediates protective effect of cardiotonic pills against rat heart ischemia/reperfusion injury," Evidence-Based Complementary and Alternative Medicine, vol. 2013, Article ID 728020, 15 pages, 2013.

[188] Y. Y. Cheng, D. Luo, Z. Xia, H. F. Tse, X. Li, and J. Rong, "In vivo cardioprotective effects and pharmacokinetic profile of n-propyl caffeamide against ischemia reperfusion injury," Archivum Immunologiae et Therapiae Experimentalis (Warsz), vol. 65, no. 2, pp. 145-156, 2017.

[189] S. Al-Salam and S. Hashmi, "Myocardial ischemia reperfusion injury: apoptotic, inflammatory and oxidative stress role of galectin-3," Cellular Physiology and Biochemistry, vol. 50, no. 3, pp. 1123-1139, 2018.

[190] G. Chang, Y. Chen, H. Zhang, and W. Zhou, "Trans sodium crocetinate alleviates ischemia/reperfusioninduced myocardial oxidative stress and apoptosis via the SIRT3/FOXO3a/SOD2 signaling pathway," International Immunopharmacology, vol. 71, pp. 361-371, 2019. 
[191] A. Brunet, L. B. Sweeney, J. F. Sturgill, K. F. Chua, P. L. Greer, and Y. Lin, "Stress-dependent regulation of FOXO transcription factors by the SIRT1 deacetylase," Science, vol. 303, no. 5666, pp. 2011-2015, 2004.

[192] H. Daitoku, M. Hatta, H. Matsuzaki, S. Aratani, T. Ohshima, and M. Miyagishi, "Silent information regulator 2 potentiates Foxo1-mediated transcription through its deacetylase activity," Proceedings of the National Academy of Sciences of the United States of America, vol. 101, no. 27, pp. 10042-10047, 2004.

[193] L. Yu, Q. Li, B. Yu, Y. Yang, Z. Jin, and W. Duan, "Berberine attenuates myocardial ischemia/reperfusion injury by reducing oxidative stress and inflammation response: role of silent information regulator 1," Oxidative Medicine and Cellular Longevity, vol. 2016, Article ID 1689602, 16 pages, 2016.

[194] Z. Wang, J. Yu, J. Wu, F. Qi, H. Wang, and Z. Wang, "Scutellarin protects cardiomyocyte ischemia-reperfusion injury by reducing apoptosis and oxidative stress," Life Sciences, vol. 157, pp. 200-207, 2016.

[195] H. Liu, L. Yang, H. J. Wu, K. H. Chen, F. Lin, and G. Li, "Water-soluble acacetin prodrug confers significant cardioprotection against ischemia/reperfusion injury," Scientific Reports, vol. 6, p. 36435, 2016.

[196] Y. Murohara, Y. Yui, R. Hattori, and C. Kawai, "Effects of superoxide dismutase on reperfusion arrhythmias and left ventricular function in patients undergoing thrombolysis for anterior wall acute myocardial infarction," The American Journal of Cardiology, vol. 67, no. 8, pp. 765-767, 1991.

[197] J. Sochman, J. Vrbská, B. Musilová, and M. Rocek, "Infarct size limitation: acute $\mathrm{N}$-acetylcysteine defense (ISLAND trial): preliminary analysis and report after the first 30 patients," Clinical Cardiology, vol. 19, no. 2, pp. 94-100, 1996.

[198] K. G. Rajesh, S. Sasaguri, R. Suzuki, and H. Maeda, "Antioxidant MCI-186 inhibits mitochondrial permeability transition pore and upregulates Bcl-2 expression," American Journal of Physiology. Heart and Circulatory Physiology, vol. 285, no. 5, pp. H2171-H2178, 2003.

[199] M. Bartekova, M. Barancik, K. Ferenczyova, and N. S. Dhalla, "Beneficial effects of $\mathrm{N}$-acetylcysteine and Nmercaptopropionylglycine on ischemia reperfusion injury in the heart," Current Medicinal Chemistry, vol. 25, no. 3, pp. 355-366, 2018.

[200] C. Tong, C. Peng, L. Wang, L. Zhang, X. Yang, and P. Xu, "Intravenous administration of lycopene, a tomato extract, protects against myocardial ischemia-reperfusion injury," Nutrients, vol. 8, no. 3, p. 138, 2016.

[201] Z. Broskova and V. Knezl, "Protective effect of novel pyridoindole derivatives on ischemia/reperfusion injury of the isolated rat heart," Pharmacological Reports, vol. 63, no. 4, pp. 967-974, 2011.

[202] R. C. Dage, B. A. Anderson, S. J. Mao, and J. E. Koerner, "Probucol reduces myocardial dysfunction during reperfusion after short-term ischemia in rabbit heart," Journal of Cardiovascular Pharmacology, vol. 17, no. 1, pp. 158-165, 1991.

[203] R. A. Smith and M. P. Murphy, "Animal and human studies with the mitochondria-targeted antioxidant MitoQ," Annals of the New York Academy of Sciences, vol. 1201, pp. 96-103, 2010.

[204] V. J. Adlam, J. C. Harrison, C. M. Porteous, A. M. James, R. A. Smith, and M. P. Murphy, "Targeting an antioxidant to mitochondria decreases cardiac ischemia-reperfusion injury," The FASEB Journal, vol. 19, no. 9, pp. 1088-1095, 2005.
[205] K. Zhao, G. M. Zhao, D. Wu, Y. Soong, A. V. Birk, and P. W. Schiller, "Cell-permeable peptide antioxidants targeted to inner mitochondrial membrane inhibit mitochondrial swelling, oxidative cell death, and reperfusion injury," The Journal of Biological Chemistry, vol. 279, no. 33, pp. 34682-34690, 2004.

[206] H. H. Szeto, "Mitochondria-targeted cytoprotective peptides for ischemia-reperfusion injury," Antioxidants \& Redox Signaling, vol. 10, no. 3, pp. 601-619, 2008.

[207] Z. Wang, K. Chen, Y. Han, H. Zhu, X. Zhou, and T. Tan, "Irisin protects heart against ischemia-reperfusion injury through a SOD2-dependent mitochondria mechanism," Journal of Cardiovascular Pharmacology, vol. 72, no. 6, pp. 259-269, 2018.

[208] L. Valls-Lacalle, I. Barba, E. Miró-Casas, J. J. AlburquerqueBéjar, M. Ruiz-Meana, and M. Fuertes-Agudo, "Succinate dehydrogenase inhibition with malonate during reperfusion reduces infarct size by preventing mitochondrial permeability transition," Cardiovascular Research, vol. 109, no. 3, pp. 374384, 2016.

[209] L. Cominacini, C. Mozzini, U. Garbin, A. Pasini, C. Stranieri, and E. Solani, "Endoplasmic reticulum stress and Nrf2 signaling in cardiovascular diseases," Free Radical Biology and Medicine, vol. 88, no. Part B, pp. 233-242, 2015.

[210] J. W. Kaspar, S. K. Niture, and A. K. Jaiswal, "Nrf2:INrf2 (Keap1) signaling in oxidative stress," Free Radical Biology \& Medicine, vol. 47, no. 9, pp. 1304-1309, 2009.

[211] L. Cheng, Z. Jin, R. Zhao, K. Ren, C. Deng, and S. Yu, "Resveratrol attenuates inflammation and oxidative stress induced by myocardial ischemia-reperfusion injury: role of Nrf2/ARE pathway," International Journal of Clinical and Experimental Medicine, vol. 8, no. 7, pp. 10420-10428, 2015.

[212] I. Buendia, P. Michalska, E. Navarro, I. Gameiro, J. Egea, and R. León, "Nrf2-ARE pathway: an emerging target against oxidative stress and neuroinflammation in neurodegenerative diseases," Pharmacology \& Therapeutics, vol. 157, pp. 84104, 2016.

[213] Z. Peng, R. Zhang, L. Pan, H. Pei, Z. Niu, and H. Wang, "Glaucocalyxin A protects H9c2 cells against hypoxia/reoxygenation-induced injury through the activation of Akt/Nrf2/HO-1 pathway," Cell Transplantation, vol. 29, article 963689720967672, 2020.

[214] H. Yu, L. Shi, S. Zhao, Y. Sun, Y. Gao, and Y. Sun, “Triptolide attenuates myocardial ischemia/reperfusion injuries in rats by inducing the activation of Nrf2/HO-1 defense pathway," Cardiovascular Toxicology, vol. 16, no. 4, pp. 325-335, 2016.

[215] A. Enayati, N. Yassa, Z. Mazaheri, M. Rajaei, M. Pourabouk, and S. Ghorghanlu, "Cardioprotective and anti-apoptotic effects of Potentilla reptans L. root via Nrf2 pathway in an isolated rat heart ischemia/reperfusion model," Life Sciences, vol. 215, pp. 216-226, 2018.

[216] S. X. Liu, Y. Zhang, Y. F. Wang, X. C. Li, M. X. Xiang, and C. Bian, "Upregulation of heme oxygenase-1 expression by hydroxysafflor yellow A conferring protection from anoxia/reoxygenation-induced apoptosis in H9c2 cardiomyocytes," International Journal of Cardiology, vol. 160, no. 2, pp. 95-101, 2012.

[217] X. Shi, G. Tao, L. Ji, and G. Tian, "Sappanone A protects against myocardial ischemia reperfusion injury by modulation of Nrf2," Drug Design, Development and Therapy, vol. 14, pp. 61-71, 2020. 
[218] L. Yu, S. Li, X. Tang, Z. Li, J. Zhang, and X. Xue, "Diallyl trisulfide ameliorates myocardial ischemia-reperfusion injury by reducing oxidative stress and endoplasmic reticulum stress-mediated apoptosis in type 1 diabetic rats: role of SIRT1 activation," Apoptosis, vol. 22, no. 7, pp. 942-954, 2017.

[219] A. K. Jain and A. K. Jaiswal, "GSK-3beta acts upstream of Fyn kinase in regulation of nuclear export and degradation of NFE2 related factor 2," The Journal of Biological Chemistry, vol. 282, no. 22, pp. 16502-16510, 2007.

[220] A. I. Rojo, O. N. Medina-Campos, P. Rada, A. Zúñiga-Toalá, A. López-Gazcón, and S. Espada, "Signaling pathways activated by the phytochemical nordihydroguaiaretic acid contribute to a Keap1-independent regulation of Nrf2 stability: role of glycogen synthase kinase-3," Free Radical Biology \& Medicine, vol. 52, no. 2, pp. 473-487, 2012.

[221] P. Rada, A. I. Rojo, S. Chowdhry, M. McMahon, J. D. Hayes, and A. Cuadrado, "SCF/\{beta\}-TrCP promotes glycogen synthase kinase 3-dependent degradation of the Nrf2 transcription factor in a Keap1-independent manner," Molecular and Cellular Biology, vol. 31, no. 6, pp. 1121-1133, 2011.

[222] K. Shanmugam, S. Ravindran, G. A. Kurian, and M. Rajesh, "Fisetin confers cardioprotection against myocardial ischemia reperfusion injury by suppressing mitochondrial oxidative stress and mitochondrial dysfunction and inhibiting glycogen synthase kinase $3 \beta$ activity," Oxidative Medicine and Cellular Longevity, vol. 2018, Article ID 9173436, 16 pages, 2018.

[223] K. R. Laderoute, "The interaction between HIF-1 and AP-1 transcription factors in response to low oxygen," Seminars in Cell \& Developmental Biology, vol. 16, no. 4-5, pp. 502513, 2005.

[224] J. Blanco Pampín, S. A. García Rivero, X. L. Otero Cepeda, A. Vázquez Boquete, J. Forteza Vila, and R. Hinojal Fonseca, "Immunohistochemical expression of HIF-1alpha in response to early myocardial ischemia," Journal of Forensic Sciences, vol. 51, no. 1, pp. 120-124, 2006.

[225] Q. Parisi, G. G. Biondi-Zoccai, A. Abbate, D. Santini, F. Vasaturo, and S. Scarpa, "Hypoxia inducible factor-1 expression mediates myocardial response to ischemia late after acute myocardial infarction," International Journal of Cardiology, vol. 99, no. 2, pp. 337-339, 2005.

[226] N. S. Chandel, D. S. McClintock, C. E. Feliciano, T. M. Wood, J. A. Melendez, and A. M. Rodriguez, "Reactive oxygen species generated at mitochondrial complex III stabilize hypoxia-inducible factor-1alpha during hypoxia: a mechanism of $\mathrm{O}_{2}$ sensing," The Journal of Biological Chemistry, vol. 275, no. 33, pp. 25130-25138, 2000.

[227] J. J. Haddad and S. C. Land, “A non-hypoxic, ROS-sensitive pathway mediates TNF-alpha-dependent regulation of HIF1alpha," FEBS Letters, vol. 505, no. 2, pp. 269-274, 2001.

[228] Z. Cai, H. Zhong, M. Bosch-Marce, K. Fox-Talbot, L. Wang, and C. Wei, "Complete loss of ischaemic preconditioninginduced cardioprotection in mice with partial deficiency of HIF-1 alpha," Cardiovascular Research, vol. 77, no. 3, pp. 463-470, 2008.

[229] Z. P. Yu, H. Q. Yu, J. Li, C. Li, X. Hua, and X. S. Sheng, “Troxerutin attenuates oxygen-glucose deprivation and reoxygenation-induced oxidative stress and inflammation by enhancing the PI3K/AKT/HIF- $1 \alpha$ signaling pathway in H9C2 cardiomyocytes," Molecular Medicine Reports, vol. 22, no. 2, pp. 1351-1361, 2020.
[230] X. Mao, T. Wang, Y. Liu, M. G. Irwin, J. S. Ou, and X. L. Liao, "N-acetylcysteine and allopurinol confer synergy in attenuating myocardial ischemia injury via restoring HIF- $1 \alpha / \mathrm{HO}-1$ signaling in diabetic rats," PLoS One, vol. 8, no. 7, article e68949, 2013.

[231] Q. Yu, F. Gao, and X. L. Ma, "Insulin says NO to cardiovascular disease," Cardiovascular Research, vol. 89, no. 3, pp. 516524, 2011.

[232] H. Yao, X. Han, and X. Han, "The cardioprotection of the insulin-mediated PI3K/Akt/mTOR signaling pathway," American Journal of Cardiovascular Drugs, vol. 14, no. 6, pp. 433-442, 2014.

[233] Y. H. Pei, J. Chen, L. Xie, X. M. Cai, R. H. Yang, and X. Wang, "Hydroxytyrosol protects against myocardial ischemia/reperfusion injury through a PI3K/Akt-dependent mechanism," Mediators of Inflammation, vol. 2016, Article ID 1232103, 9 pages, 2016.

[234] M. M. Mocanu and D. M. Yellon, "PTEN, the Achilles' heel of myocardial ischaemia/reperfusion injury?," British Journal of Pharmacology, vol. 150, no. 7, pp. 833-838, 2007.

[235] Z. Cai and G. L. Semenza, "PTEN activity is modulated during ischemia and reperfusion: involvement in the induction and decay of preconditioning," Circulation Research, vol. 97, no. 12, pp. 1351-1359, 2005.

[236] X. H. Sun, X. Wang, Y. Zhang, and J. Hui, "Exosomes of bone-marrow stromal cells inhibit cardiomyocyte apoptosis under ischemic and hypoxic conditions via miR-486-5p targeting the PTEN/PI3K/AKT signaling pathway," Thrombosis Research, vol. 177, pp. 23-32, 2019.

[237] R. Tie, L. Ji, Y. Nan, W. Wang, X. Liang, and F. Tian, “Achyranthes bidentata polypeptides reduces oxidative stress and exerts protective effects against myocardial ischemic/reperfusion injury in rats," International Journal of Molecular Sciences, vol. 14, no. 10, pp. 19792-19804, 2013.

[238] X. Li, A. Bilali, R. Qiao, T. Paerhati, and Y. Yang, "Association of the PPAR $\gamma / \mathrm{PI} 3 \mathrm{~K} / \mathrm{Akt}$ pathway with the cardioprotective effects of tacrolimus in myocardial ischemic/reperfusion injury," Molecular Medicine Reports, vol. 17, no. 5, pp. 6759-6767, 2018.

[239] T. Ravingerová, S. Carnická, V. Ledvényiová, E. Barlaka, E. Galatou, and A. Chytilová, "Upregulation of genes involved in cardiac metabolism enhances myocardial resistance to ischemia/reperfusion in the rat heart," Physiological Research, vol. 62, Suppl 1, pp. S151-S163, 2013.

[240] R. Chen, T. Chen, T. Wang, X. Dai, K. Meng, and S. Zhang, "Tongmai Yangxin pill reduces myocardial no-reflow by regulating apoptosis and activating PI3K/Akt/eNOS pathway," Journal of Ethnopharmacology, vol. 261, p. 113069, 2020.

[241] F. Arslan, R. C. Lai, M. B. Smeets, L. Akeroyd, A. Choo, and E. N. Aguor, "Mesenchymal stem cell-derived exosomes increase ATP levels, decrease oxidative stress and activate PI3K/Akt pathway to enhance myocardial viability and prevent adverse remodeling after myocardial ischemia/reperfusion injury," Stem Cell Research, vol. 10, no. 3, pp. 301-312, 2013.

[242] J. Roy, J. Fauconnier, C. Oger, C. Farah, C. AngebaultProuteau, and J. Thireau, "Non-enzymatic oxidized metabolite of DHA, 4(RS)-4-F(4t)-neuroprostane protects the heart against reperfusion injury," Free Radical Biology \& Medicine, vol. 102, pp. 229-239, 2017.

[243] W. Qian, X. Xiong, Z. Fang, H. Lu, and Z. Wang, "Protective effect of tetramethylpyrazine on myocardial ischemia- 
reperfusion injury," Evidence-Based Complementary and Alternative Medicine, vol. 2014, Article ID 107501, 9 pages, 2014.

[244] H. Ardehali and B. O'Rourke, "Mitochondrial K(ATP) channels in cell survival and death," Journal of Molecular and Cellular Cardiology, vol. 39, no. 1, pp. 7-16, 2005.

[245] Y. Wang and M. Ashraf, "Role of protein kinase C in mitochondrial KATP channel-mediated protection against Ca2+ overload injury in rat myocardium," Circulation Research, vol. 84, no. 10, pp. 1156-1165, 1999.

[246] L. Testai, S. Rapposelli, A. Martelli, M. C. Breschi, and V. Calderone, "Mitochondrial potassium channels as pharmacological target for cardioprotective drugs," Medicinal Research Reviews, vol. 35, no. 3, pp. 520-553, 2015.

[247] L. Testai, A. Marino, I. Piano et al., "The novel H(2)S-donor 4-carboxyphenyl isothiocyanate promotes cardioprotective effects against ischemia/reperfusion injury through activation of mitoK(ATP) channels and reduction of oxidative stress," Pharmacological research, vol. 113, no. Part A, pp. 290-299, 2016.

[248] W. Wei, Y. Liu, Q. Zhang, Y. Wang, X. Zhang, and H. Zhang, "Danshen-enhanced cardioprotective effect of cardioplegia on ischemia reperfusion injury in a human-induced pluripotent stem cell-derived cardiomyocytes model," Artificial Organs, vol. 41, no. 5, pp. 452-460, 2017.

[249] F. Prunier, Y. Kawase, D. Gianni, C. Scapin, S. B. Danik, and P. T. Ellinor, "Prevention of ventricular arrhythmias with sarcoplasmic reticulum Ca2+ ATPase pump overexpression in a porcine model of ischemia reperfusion," Circulation, vol. 118, no. 6, pp. 614-624, 2008.

[250] M. L. Joiner, O. M. Koval, J. Li, B. J. He, C. Allamargot, and Z. Gao, "CaMKII determines mitochondrial stress responses in heart," Nature, vol. 491, no. 7423, pp. 269-273, 2012.

[251] H. Zhang, X. Wang, Y. Ma, and Y. Shi, "The effect of ginsenoside RB1, diazoxide, and 5-hydroxydecanoate on hypoxia-reoxygenation injury of $\mathrm{H} 9 \mathrm{C} 2$ cardiomyocytes," Evidence-Based Complementary and Alternative Medicine, vol. 2019, Article ID 6046405, 12 pages, 2019.

[252] C. P. Baines, "The mitochondrial permeability transition pore and ischemia-reperfusion injury," Basic Research in Cardiology, vol. 104, no. 2, pp. 181-188, 2009.

[253] S. B. Ong, P. Samangouei, S. B. Kalkhoran, and D. J. Hausenloy, "The mitochondrial permeability transition pore and its role in myocardial ischemia reperfusion injury," Journal of Molecular and Cellular Cardiology, vol. 78, pp. 23-34, 2015.

[254] D. J. Hausenloy, S. B. Ong, and D. M. Yellon, "The mitochondrial permeability transition pore as a target for preconditioning and postconditioning," Basic Research in Cardiology, vol. 104, no. 2, pp. 189-202, 2009.

[255] S. W. Schaffer, C. J. Jong, T. Ito, and J. Azuma, "Effect of taurine on ischemia-reperfusion injury," Amino Acids, vol. 46, no. 1, pp. 21-30, 2014.

[256] L. Gomez, H. Thibault, A. Gharib, J. M. Dumont, G. Vuagniaux, and P. Scalfaro, "Inhibition of mitochondrial permeability transition improves functional recovery and reduces mortality following acute myocardial infarction in mice," American Journal of Physiology. Heart and Circulatory Physiology, vol. 293, no. 3, pp. H1654-H1661, 2007.

[257] G. Ikeda, T. Matoba, Y. Nakano, K. Nagaoka, A. Ishikita, and K. Nakano, "Nanoparticle-mediated targeting of cyclosporine A enhances cardioprotection against ischemia-reperfusion injury through inhibition of mitochondrial permeability transition pore opening," Scientific Reports, vol. 6, p. 20467, 2016.

[258] T. Bochaton, C. Crola-Da-Silva, B. Pillot, C. Villedieu, L. Ferreras, and M. R. Alam, "Inhibition of myocardial reperfusion injury by ischemic postconditioning requires sirtuin 3mediated deacetylation of cyclophilin D," Journal of Molecular and Cellular Cardiology, vol. 84, pp. 61-69, 2015.

[259] C. Chen, W. Chen, Z. Nong, Y. Ma, S. Qiu, and G. Wu, "Cardioprotective effects of combined therapy with hyperbaric oxygen and diltiazem pretreatment on myocardial ischemia-reperfusion injury in rats," Cellular Physiology and Biochemistry, vol. 38, no. 5, pp. 2015-2029, 2016.

[260] J. Misao, Y. Hayakawa, M. Ohno, S. Kato, T. Fujiwara, and H. Fujiwara, "Expression of bcl-2 protein, an inhibitor of apoptosis, and Bax, an accelerator of apoptosis, in ventricular myocytes of human hearts with myocardial infarction," Circulation, vol. 94, no. 7, pp. 1506-1512, 1996.

[261] C. Chen, W. Lu, G. Wu, L. Lv, W. Chen, and L. Huang, "Cardioprotective effects of combined therapy with diltiazem and superoxide dismutase on myocardial ischemia-reperfusion injury in rats," Life Sciences, vol. 183, pp. 50-59, 2017.

[262] Q. Yu, X. Li, and X. Cao, "Cardioprotective effects of phenylethanoid glycoside-rich extract from Cistanche deserticola in ischemia-reperfusion-induced myocardial infarction in rats," Annals of Vascular Surgery, vol. 34, pp. 234-242, 2016.

[263] K. Kato, H. Yin, J. Agata, H. Yoshida, L. Chao, and J. Chao, "Adrenomedullin gene delivery attenuates myocardial infarction and apoptosis after ischemia and reperfusion," American Journal of Physiology. Heart and Circulatory Physiology, vol. 285, no. 4, pp. H1506-H1514, 2003.

[264] D. Wang, T. Chen, and F. Liu, "Betulinic acid alleviates myocardial hypoxia/reoxygenation injury via inducing Nrf2/HO1 and inhibiting p38 and JNK pathways," European Journal of Pharmacology, vol. 838, pp. 53-59, 2018.

[265] S. K. Ding, L. X. Wang, L. S. Guo, P. Luo, J. J. Du, and Z. L. Zhao, "Syringic acid inhibits apoptosis pathways via downregulation of p38MAPK and JNK signaling pathways in $\mathrm{H} 9 \mathrm{c} 2$ cardiomyocytes following hypoxia/reoxygenation injury," Molecular Medicine Reports, vol. 16, no. 2, pp. 2290-2294, 2017.

[266] G. Yang, D. Min, J. Yan, M. Yang, and G. Lin, "Protective role and mechanism of snakegourd peel against myocardial infarction in rats," Phytomedicine, vol. 42, pp. 18-24, 2018.

[267] D. Shen, R. Chen, L. Zhang, Z. Rao, Y. Ruan, and L. Li, "Sulodexide attenuates endoplasmic reticulum stress induced by myocardial ischaemia/reperfusion by activating the PI3K/Akt pathway," Journal of Cellular and Molecular Medicine, vol. 23, no. 8, pp. 5063-5075, 2019.

[268] Y. Yu, N. Xing, X. Xu, Y. Zhu, S. Wang, and G. Sun, "Tournefolic acid B, derived from Clinopodium chinense (Benth.) Kuntze, protects against myocardial ischemia/reperfusion injury by inhibiting endoplasmic reticulum stress-regulated apoptosis via PI3K/AKT pathways," Phytomedicine, vol. 52, pp. 178-186, 2019.

[269] L. Valentim, K. M. Laurence, P. A. Townsend, C. J. Carroll, S. Soond, and T. M. Scarabelli, "Urocortin inhibits Beclin1mediated autophagic cell death in cardiac myocytes exposed to ischaemia/reperfusion injury," Journal of Molecular and Cellular Cardiology, vol. 40, no. 6, pp. 846-852, 2006.

[270] J. L. Wang, Y. Z. Li, T. Q. Tao, X. R. Wang, Y. Wang, and D. D. Song, "Postconditioning with calreticulin attenuates 
myocardial ischemia/reperfusion injury and improves autophagic flux," Shock, vol. 53, no. 3, pp. 363-372, 2020.

[271] Y. Wang, Z. Yang, G. Zheng, L. Yu, Y. Yin, and N. Mu, "Metformin promotes autophagy in ischemia/reperfusion myocardium via cytoplasmic AMPK $\alpha 1$ and nuclear AMPK $\alpha 2$ pathways," Life Sciences, vol. 225, pp. 64-71, 2019.

[272] L. Hong, Y. Sun, J. Z. An, C. Wang, and S. G. Qiao, “Sevoflurane preconditioning confers delayed cardioprotection by upregulating AMP-activated protein kinase levels to restore autophagic flux in ischemia-reperfusion rat hearts," Medical Science Monitor, vol. 26, article e922176, 2020.

[273] R. J. Godar, X. Ma, H. Liu, J. T. Murphy, C. J. Weinheimer, and A. Kovacs, "Repetitive stimulation of autophagylysosome machinery by intermittent fasting preconditions the myocardium to ischemia-reperfusion injury," Autophagy, vol. 11, no. 9, pp. 1537-1560, 2015.

[274] J. Li, X. Xiang, and Z. Xu, "Cilostazol protects against myocardial ischemia and reperfusion injury by activating transcription factor EB (TFEB)," Biotechnology and Applied Biochemistry, vol. 66, no. 4, pp. 555-563, 2019.

[275] J. Sadoshima, "The role of autophagy during ischemia/reperfusion," Autophagy, vol. 4, no. 4, pp. 402-403, 2008.

[276] S. Marek-Iannucci, A. Thomas, J. Hou, A. Crupi, J. Sin, and D. J. Taylor, "Myocardial hypothermia increases autophagic flux, mitochondrial mass and myocardial function after ischemia-reperfusion injury," Scientific reports, vol. 9, no. 1, p. 10001, 2019.

[277] P. Yu, J. Zhang, S. Yu, Z. Luo, F. Hua, and L. Yuan, "Protective effect of sevoflurane postconditioning against cardiac ischemia/reperfusion injury via ameliorating mitochondrial impairment, oxidative stress and rescuing autophagic clearance," PLoS One, vol. 10, no. 8, article e0134666, 2015.

[278] H. H. Su, Y. C. Chu, J. M. Liao, Y. H. Wang, M. S. Jan, and C. W. Lin, "Phellinus linteus mycelium alleviates myocardial ischemia-reperfusion injury through autophagic regulation," Frontiers in Pharmacology, vol. 8, p. 175, 2017.

[279] Y. Li, H. Zhang, Z. Li, X. Yan, Y. Li, and S. Liu, "microRNA$130 a-5 p$ suppresses myocardial ischemia reperfusion injury by downregulating the HMGB2/NF- $\kappa \mathrm{B}$ axis," BMC Cardiovascular Disorders, vol. 21, no. 1, p. 121, 2021.

[280] S. Tanguy, A. Rakotovao, M. G. Jouan, C. Ghezzi, J. de Leiris, and F. Boucher, "Dietary selenium intake influences Cx43 dephosphorylation, TNF- $\alpha$ expression and cardiac remodeling after reperfused infarction," Molecular Nutrition \& Food Research, vol. 55, no. 4, pp. 522-529, 2011. 